OPEN ACCESS

Edited by: Varenyam Achal, East China Normal University, China

Reviewed by:

John L. Provis, University of Sheffield, UK Zeynep Basaran Bundur, Ozyegin University, Turkey

*Correspondence:

Nele De Belie nele.debelie@ugent.be

Specialty section:

This article was submitted to Microbiotechnology, Ecotoxicology and Bioremediation,

a section of the journal

Frontiers in Microbiology

Received: 18 September 2015

Accepted: 20 October 2015

Published: 04 November 2015

Citation:

Erşan YÇ, Gruyaert E, Louis G, Lors

C. De Belie N and Boon N (2015) Self-protected nitrate reducing culture for intrinsic repair of concrete cracks.

Front. Microbiol. 6:1228.

doi: 10.3389/fmicb.2015.01228

\section{Self-protected nitrate reducing culture for intrinsic repair of concrete cracks}

\author{
Yusuf Ç. Erşan ${ }^{1,2}$, Elke Gruyaert ${ }^{2}$, Ghislain Louis ${ }^{3}$, Christine Lors $^{3}$, Nele De Belie ${ }^{2 *}$ and \\ Nico Boon ${ }^{1}$ \\ 1 Laboratory of Microbial Ecology and Technology, Department of Biochemical and Microbial Technology, Ghent University, \\ Ghent, Belgium, ${ }^{2}$ Magnel Laboratory for Concrete Research, Department of Structural Engineering, Ghent University, Ghent, \\ Belgium, ${ }^{3}$ Département Génie Civil et Environnemental, Ecole Nationale Supérieure des Mines de Douai, Douai, France
}

Attentive monitoring and regular repair of concrete cracks are necessary to avoid further durability problems. As an alternative to current maintenance methods, intrinsic repair systems which enable self-healing of cracks have been investigated. Exploiting microbial induced $\mathrm{CaCO}_{3}$ precipitation (MICP) using (protected) axenic cultures is one of the proposed methods. Yet, only a few of the suggested healing agents were economically feasible for in situ application. This study presents a $\mathrm{NO}_{3}^{-}$reducing self-protected enrichment culture as a self-healing additive for concrete. Concrete admixtures $\mathrm{Ca}\left(\mathrm{NO}_{3}\right)_{2}$ and $\mathrm{Ca}(\mathrm{HCOO})_{2}$ were used as nutrients. The enrichment culture, grown as granules (0.5-2 mm) consisting of $70 \%$ biomass and 30\% inorganic salts were added into mortar without any additional protection. Upon 28 days curing, mortar specimens were subjected to direct tensile load and multiple cracks $(0.1-0.6 \mathrm{~mm})$ were achieved. Cracked specimens were immersed in water for 28 days and effective crack closure up to $0.5 \mathrm{~mm}$ crack width was achieved through calcite precipitation. Microbial activity during crack healing was monitored through weekly NOx analysis which revealed that $92 \pm 2 \%$ of the available $\mathrm{NO}_{3}^{-}$was consumed. Another set of specimens were cracked after 6 months curing, thus the effect of curing time on healing efficiency was investigated, and mineral formation at the inner crack surfaces was observed, resulting in $70 \%$ less capillary water absorption compared to healed control specimens. In conclusion, enriched mixed denitrifying cultures structured in self-protecting granules are very promising strategies to enhance microbial self-healing.

Keywords: self-encapsulated, self-healing, microbial concrete, indentation, mechanical properties, denitrifying culture, admixtures

\section{INTRODUCTION}

Cracking of concrete is inevitable due to its heterogeneous matrix and brittle nature. Early age cracks in concrete mostly occur a few days after casting and facilitate the migration of aggressive substances toward the steel reinforcement. Microbial induced $\mathrm{CaCO}_{3}$ precipitation (MICP) became a popular research topic and an effective strategy for autonomous healing of concrete cracks. As described so far, typical components of a healing agent in microbial self-healing concrete are the bacterial agent, a protective carrier and the necessary nutrients for stimulation of bacterial activity 
(Wiktor and Jonkers, 2011; Achal et al., 2013; Wang et al., 2014a,b). Recent advances in bacteria-based self-healing concrete brought the technology closer to application. For instance, in 2014, a large scale application of self-healing concrete took place in Ecuador (Sierra-Beltran et al., 2015), yet the performance is unknown. Axenic cultures having specific traits are the main interest as bacterial agents by now (Wiktor and Jonkers, 2011; Achal et al., 2013; Wang et al., 2014a,b). On the one hand, using an axenic culture is important to evidence the potential of proposed microbial pathways for their use in microbial self-healing concrete. Moreover, the use of axenic cultures eases the control of the process and minimizes unexpected results. On the other hand, using either of the currently proposed axenic strains as bacterial agents results in a considerable increase in the cost of the product (Silva et al., 2015a). Several options can be considered to decrease the cost of the healing agent (protected bacteria+nutrients) such as using commercially available protective carriers instead of microcapsules, or decreasing the amount of bacterial agent used depending on the expectations of the manufacturer. Differently, replacing axenic cultures by non-axenic cultures that are derived from side-streams can be a feasible alternative. In a recent study, Silva et al. (2015b) revealed that non-axenic cultures can also be produced to follow a single pathway by applying selective processes and thus the production cost can be decreased 40 times. Furthermore, in terms of the provided self-healing performance up to $400 \mu \mathrm{m}$ crack width, the non-axenic ureolytic powder appeared to be as effective as Bacillus sphaericus which is one of the most popular axenic strains used in self-healing concrete studies (Wang et al., 2014a; Silva et al., 2015b). Moreover, the culture is reported to be a self-protected culture avoiding use of protective carriers for concrete application (Erşan et al., 2015c; Silva et al., 2015b). Since the concrete industry demands inexpensive solutions for durability issues, use of self-protected non-axenic cultures can pave the way for application of microbial self-healing concrete.

Apart from ureolysis, aerobic respiration and anoxic oxidation of organic carbon through $\mathrm{NO}_{3}^{-}$reduction are the two other pathways that are proven to be useful for development of microbial self-healing concrete (Wiktor and Jonkers, 2011; Erşan et al., 2015b). Wiktor and Jonkers (2011) reported crack closure up to $460 \mu \mathrm{m}$ in 100 days for mortar specimens containing bacteria loaded light-weight aggregates. It is also known that the $\mathrm{NO}_{3}^{-}$reduction pathway leads to $\mathrm{CaCO}_{3}$ precipitation and in our previous work $\mathrm{CaCO}_{3}$ yields up to $18.9 \mathrm{~g} \mathrm{CaCO}_{3} / \mathrm{g} \mathrm{NO}_{3}-\mathrm{N}$ were achieved by only using the concrete admixtures $\mathrm{Ca}(\mathrm{HCOO})_{2}$ and $\mathrm{Ca}\left(\mathrm{NO}_{3}\right)_{2}$ as nutrients (Erşan et al., 2015a). Moreover, $\mathrm{NO}_{3}^{-}$reducing axenic strains could induce closure of concrete cracks up to $400 \mu \mathrm{m}$ in 28 days (Erşan et al., 2015b). However, studies investigating these pathways are limited to use of axenic cultures. Therefore, it is necessary to produce and test selfprotected non-axenic cultures that are able to follow the $\mathrm{NO}_{3}^{-}$ reduction pathway for development of microbial self-healing concrete.

Granular bacterial cultures can be an option for use of non-axenic cultures in concrete. One of the main advantages of granulated cultures is the systematic placement of cultures in a compact form (Gao et al., 2011). For instance granules can consist of aerobic heterotrophs, denitrifiers, poly-phosphate accumulating bacteria, and nitrifiers at the same time (Gao et al., 2011). Depending on the cultivation process, selective enrichment of the certain type of species in a granulated culture is possible. Moreover, the compact form and the layered structure of granular biomass is advantageous for protection of the bacteria at the core (Erşan and Erguder, 2014). Studies revealed that granulated bacteria can be dried, stored, and re-activated in case of necessity (Lv et al., 2013). Therefore, it is possible to achieve a self-protected nitrate reducing community for concrete application by using the granulation phenomenon.

For such need, special granules called "activated compact denitrifying core" (ACDC) were cultivated in this study. Previous investigations revealed that ACDC can survive mortar incorporation, inhibits steel corrosion and is compatible with concrete (Erşan et al., 2015c, accepted). Yet, the self-healing performances of mortar specimens containing ACDC granules have not been tested. Therefore, it is necessary to investigate ACDC for development of microbial self-healing concrete. Furthermore, to our knowledge, microbial self-healing concrete studies are mostly limited to curing periods up to 56 days (Wiktor and Jonkers, 2011; Wang et al., 2014a,c) which is far from the concrete ages in situ. Thus, the self-healing performance of bacteria-based concrete at the long term is still a question. Accordingly the study was conducted in two consecutive steps (1) assessing the self-healing performance of mortar specimens containing ACDC, (2) assessing the self-healing performance of concrete cracks occurring after 6 months curing.

\section{MATERIALS AND METHODS}

\section{Cultivation of Self-protected Granular Culture}

ACDC granules were cultivated in a cylindrical sequencing batch reactor (SBR) (effective $h=30 \mathrm{~cm}, \varnothing=12.5 \mathrm{~cm}$ and $50 \%$ volume exchange ratio) by following a previously described procedure (Erşan and Erguder, 2013). The SBR was operated with anoxic/aerobic period sequence $(180 \mathrm{~min}$ anoxic and $155-168 \mathrm{~min}$ aerobic period). Since the aim was to use the granules for concrete application, the granules should be composed of bacteria that are able to reduce $\mathrm{NO}_{3}^{-}$in the absence of micronutrients and vitamins. Therefore, different from the described procedure, minimal nutrient solution (COD:N-5:1) was used as feed (4 times/day) and the solution composition is given in Table 1. Moreover, the initial $\mathrm{pH}$ of the feed solution was set between 9 and 9.5 by using concentrated $\mathrm{NaOH}$ solution (10 M). Granulation [94\% of the volatile suspended solid (VSS) content] was achieved in 4 weeks and the reactor was operated for 7 months in total. ACDC granules were harvested from the reactor at the end of 2nd, 4th, and 7th month. The harvesting times were arbitrarily chosen after achieving the stable granular biomass ( $\sim 95 \%)$ with an active denitrifying core. The harvested ACDC granules were dried for $48 \mathrm{~h}$ in a drying tunnel at $60^{\circ} \mathrm{C}$ with ventilation and stored at room temperature until the tests. 


\section{Quality Assessment of the Culture}

During the steady operation of the SBR, initial and effluent $\mathrm{NOx}-\mathrm{N}\left(\mathrm{NO}_{3}-\mathrm{N}\right.$ and $\left.\mathrm{NO}_{2}-\mathrm{N}\right)$ concentrations were monitored by sampling the arbitrary cycles. The rough composition of the ACDC granules was also monitored through volatile (VSS) and total suspended solid (TSS) analysis after full granulation (>90\% granulation). Based on the VSS:TSS ratio, ACDC granules consisted of bacteria $(0.7 \mathrm{w} / \mathrm{w})$ and inorganic matter $(0.3 \mathrm{w} / \mathrm{w})$. Throughout the manuscript, ACDC amounts are given as cell dry weight $(\mathrm{CDW})$ which represents $70 \%$ of the total ACDC amount used. The objective was to achieve granular culture containing an active denitrifying core. One of the indications of a denitrifying core is denitrification activity in the aerobic period (Erşan and Erguder, 2014) when the dissolved oxygen concentration is around $6 \mathrm{mg} / \mathrm{L}$. Therefore, the activity of the core community was monitored through kinetic NOx-N measurements with $15 \mathrm{~min}$ intervals during the aerobic period of a cycle.

\section{Preparation of the Mortar Specimens and Formation of the Cracks}

Series of mortar specimens $(30 \times 30 \times 360 \mathrm{~mm})$ with an embedded steel reinforcement bar $(\varnothing=6 \mathrm{~mm})$ were prepared by using CEM I $52.5 \mathrm{~N}$, tap water and standard sand according to the norm EN 196-1 and further cured at $20^{\circ} \mathrm{C}$ and $\mathrm{RH}>90 \%$ for 28 days and 6 months prior to cracking. The sand:cement:water ratio was 3:1:0.5. Self-healing additives consisted of nutrients and self-protected bacterial agent. Commercial concrete admixtures calcium formate $\left[\mathrm{Ca}(\mathrm{HCOO})_{2}-2 \% \mathrm{w} / \mathrm{w}\right.$ cement] and calcium nitrate $\left[\mathrm{Ca}\left(\mathrm{NO}_{3}\right)_{2}-3 \% \mathrm{w} / \mathrm{w}\right.$ cement $]$ were used as nutrients. Dry ACDC granules (0.5-2 $\mathrm{mm}$ in size) were used as bacterial agent and added into the mix during the mortar preparation. Sieving

TABLE 1 | The feed composition for cultivation of ACDC.

\begin{tabular}{lc}
\hline Compounds & Concentrations (g/L) \\
\hline $\mathrm{NaNO}_{3}$ & 1.7 \\
$\mathrm{NaHCOO}$ & 5.36 \\
$\mathrm{Ca}(\mathrm{HCOO})_{2}$ & 0.65 \\
$\mathrm{Na}_{2} \mathrm{HPO}_{4} \cdot 2 \mathrm{H}_{2} \mathrm{O}$ & 0.06 \\
$\mathrm{MgSO}_{4} \cdot 7 \mathrm{H}_{2} \mathrm{O}$ & 0.18
\end{tabular}

technique was used to achieve the portion with the desired size range. The influence of the initial amount of the bacterial agent was tested by using two different doses (either 0.5 or $1 \% \mathrm{w} / \mathrm{w}$ cement).

Cured specimens (at $20^{\circ} \mathrm{C}$ and $\mathrm{RH}>90 \%$ ) were subjected to a tensile stress by applying uniaxial tensile load at a speed of $0.01 \mathrm{~mm} / \mathrm{s}$ on the embedded steel reinforcement bar under stroke control. Multiple cracks were achieved and the load was increased until a desired average crack width was achieved. The average crack width was calculated as previously described (Wang et al., 2014c).

The mortar specimens cured for 28 days were tested for 100 $600 \mu \mathrm{m}$ crack width range. The mortar specimens cured for 6 months were tested for 100-500 $\mu \mathrm{m}$ crack width. Average crack widths of each series are given in Table 2. Following the cracking, specimens were immersed in water for 28 days at ambient temperature of $20^{\circ} \mathrm{C}$.

\section{Quantification of Self-healing Properties Crack Closure}

Crack closure was observed biweekly through stereomicroscope with Leica S8 Apo apochromatic optics (Diegem, Belgium). Obtained images were further analyzed for the decrease in crack width by using image analysis software (The Leica Application Suite, LAS 3.7). During microscopic analysis, specimens exposed to ambient air conditions $\left(\sim 20^{\circ} \mathrm{C}\right)$. Crack closure efficiency was calculated by using Equation (1).

$$
\text { Crackclosure } \%=\left[1-\left(\mathrm{w}_{\mathrm{t}} / \mathrm{w}_{\text {initial }}\right)\right] \times 100
$$

where, $w_{t}$, crack width measured at a certain time $t(d) ; w_{\text {initial }}$, initial crack width.

\section{Water Tightness}

In order to quantify the water tightness of the healed specimens capillary sorption tests were conducted as described previously (Wang, 2013). Prior to testing, the specimens were dried in an oven at $40^{\circ} \mathrm{C}$ until the mass changes in $24 \mathrm{~h}$ were less than $0.1 \%$. Similar crack widths were chosen for each specimen. Apart from the chosen crack the rest of the specimen was completely covered with aluminum tape to prevent water ingress and evaporation. Therefore, only the area of $3 \mathrm{~cm}^{2}(30 \times 10 \mathrm{~mm})$

TABLE 2 | Detailed information about the specimen series tested throughout the study.

\begin{tabular}{|c|c|c|c|c|}
\hline Series & Bacteria dose ( $\%$ w/w cement $)$ & Crack width range $(\mu \mathrm{m})$ & Average crack width $(\mu \mathrm{m} \pm$ SEM) & Age (curing time) \\
\hline Reference & N/A & $100-500$ & $280 \pm 5$ & 6 months \\
\hline & $\mathrm{N} / \mathrm{A}$ & $120-500$ & $260 \pm 5$ & 6 months \\
\hline \multirow[t]{2}{*}{ Microbial Specimen $(\mathrm{R}+\mathrm{N}+\mathrm{ACDC})^{\mathrm{a}}$} & 0.5 & $100-640$ & $400 \pm 10$ & 28 days \\
\hline & 1 & $120-500$ & $310 \pm 5$ & 6 months \\
\hline
\end{tabular}

${ }^{a} R$, Reference mortar [sand:cement:water (g)- 1350:450:225]; N, Nutrients; ACDC, Activated Compact Denitrifying Core; N/A, No addition. 
surrounding the chosen crack contacted with water. The mass increase of specimens due to the absorbed water was monitored in regular time intervals. A wet towel was used to remove the remaining surface water droplets prior to weighing. Water tightness regain was calculated by considering the water tightness of the uncracked specimen as a goal of $100 \%$ regain and the water tightness of the autogenously healed specimen as a reference. The calculations were done by following Equation (2).

$$
\begin{aligned}
& \text { Water tightness regain }(\%)= \\
& \qquad\left(1-\frac{\mathrm{m}_{\text {healed }}-\mathrm{m}_{\text {uncracked }}}{\mathrm{m}_{\text {autogenously healed }}-\mathrm{m}_{\text {uncracked }}}\right) \times 100(2)
\end{aligned}
$$

where, $\mathrm{m}_{\text {autogenouslyhealed, water absorbed after autogenous }}$ healing; $\mathrm{m}_{\text {healed }}$, water absorbed after any type of healing; $\mathrm{m}_{\text {uncracked }}$, water absorbed by uncracked specimen.

\section{Mechanical and Chemical Characteristics of the Healing Material}

A representative mortar slice was carefully sawn from each mortar bar by leaving $\sim 5 \mathrm{~mm}$ distance from the crack borders and prepared for further testing. The samples $(\sim 10 \times 25 \times$ $25 \mathrm{~mm}$ ) were embedded in Wood's alloy at their side surfaces and in epoxy resin at their top surface. The epoxy could not penetrate into the pores of the mortar specimen, only into the crack, and thus did not interfere with the mechanical properties of the calcite and C-S-H whilst indentation measurements. Surface quality is of importance for accurate determination of elastic moduli and hardness by indentation. Therefore, the specimens were gently ground using diamond grinding discs (grade 80, 220, 600 , and 1200) and polished using diamond suspensions (6, 3, and $1 \mu \mathrm{m})$ in order to obtain a smooth surface. Finally, a carbon coating was applied and the specimens were vacuum-dried before investigation.

A Hitachi S-4300SE/N SEM (Berkshire, United Kingdom), equipped with a special stage to combine the indentation technique with SEM/EDX, was used during the investigation of mechanical properties. Such a combined system was beneficial to have certainty about the test location and the mineral phase for which the mechanical properties were measured and calculated. Moreover, the chemical composition of the products formed in the crack could be verified by energy dispersive X-ray analyses (EDX). During the indentation tests, the samples were visualized in the SEM with an accelerating voltage of $10 \mathrm{kV}$ and a working distance of $35 \mathrm{~mm}$. Furthermore, images with higher resolution were obtained at an acceleration voltage of $15 \mathrm{kV}$ and a working distance of $8-10 \mathrm{~mm}$. The micrographs shown for the 28 days old specimens were obtained with the latter settings.

The indentation tests were performed using the microhardness tester of the company Kammrath and Weiss (Dortmund, Germany). The load and displacement of the diamond Berkovich indenter were monitored with an accuracy of $0.5 \mathrm{mN}$ and $1 \mathrm{~nm}$, respectively. The displacement of the indenter was determined by means of a laser, which reflects on the Wood's alloy and allows to measure very accurately the penetration of the indenter in the matrix. Moreover, the displacement values were corrected to take into account the compliance of the test frame. Tests on cement-based materials showed that the value for the compliance $\mathrm{C}_{f}$ of the used test frame is $0.000561 \mu \mathrm{m} / \mathrm{mN}$. The load cycle used for the indentation tests is given in Supplementary Figure 1. The load was increased to $25 \mathrm{mN}$ at a speed of $0.8 \mathrm{mN} / \mathrm{s}$ and held constant for $15 \mathrm{~s}$ to avoid plastic effects. Thereafter, the load was decreased at the same speed (See Supplementary Figure 1). Based on the curve presenting the load in function of the penetration depth of the indenter (See Supplementary Figure 2), the hardness could be determined without visualization of the indentation.

As the maximum penetration was always more than $400 \mathrm{~nm}$ (Chicot, 2009) the measurements were situated at the microhardness level and the Martens hardness $\mathrm{H}_{\mathrm{M}}$ [GPa] had to be calculated as the ratio of the maximum load $\mathrm{P}_{\max }[\mathrm{mN}]$ to the contact surface area $A_{c}\left[\mu \mathrm{m}^{2}\right]$ Equation (3). For a Berkovich indenter, $A_{c}$ can be calculated in function of $h_{c}$ as given by Equation (4). Equation (4) is based on the fact that the behavior of the Berkovich indenter can be modeled by a conical indenter with a half-included angle of $70.3^{\circ}$, giving the same depth-toarea relationship (Oliver and Pharr, 2004). $h_{c}[\mu \mathrm{m}]$ is the contact depth as used in the calculation of the hardness by Oliver and Pharr (Oliver and Pharr, 1992) and is calculated based on the maximum penetration depth $h_{\max }[\mu \mathrm{m}]$ (See Supplementary Figure 2).

$$
\begin{aligned}
\mathrm{H}_{\mathrm{M}} & =\frac{\mathrm{P}_{\max }}{\mathrm{A}_{\mathrm{C}}} \\
\mathrm{A}_{\mathrm{C}} & =26.43 \cdot \mathrm{h}_{\mathrm{c}}^{2} \\
\mathrm{~h}_{\mathrm{c}} & =\mathrm{h}_{\max }-\varepsilon \cdot \frac{\mathrm{P}_{\max }}{\mathrm{S}_{\mathrm{u}}} \text { with } \mathrm{S}_{\mathrm{u}}=\left(\frac{\mathrm{dP}}{\mathrm{dh}}\right)_{\mathrm{h}=\mathrm{h}_{\max }}
\end{aligned}
$$

where, $\mathrm{P}_{\max }$, the maximum load $(\mathrm{mN}) ; \mathrm{S}_{\mathrm{u}}$, the slope at the deloading curve in $\mathrm{h}=\mathrm{h}_{\max }(\mathrm{mN} / \mu \mathrm{m}) ; \varepsilon$, the geometrical constant equals to 0.75 according to Oliver and Pharr (2004).

An approximate estimation of the E-modulus could be made based on the results obtained in this study. Therefore, the reduced modulus of elasticity $\left(\mathrm{E}_{\mathrm{R}}\right)[\mathrm{GPa}]$ was first calculated with Equation (6), taking into account Equation (7).

$$
\begin{aligned}
\frac{1}{\mathrm{~S}_{\mathrm{u}}} & =\left(\frac{\mathrm{dh}}{\mathrm{dP}}\right)_{\mathrm{h}=\mathrm{hmax}}=\mathrm{C}_{\mathrm{f}}+\frac{\sqrt{\pi}}{2} \cdot \frac{1}{\beta \cdot \lambda \cdot \mathrm{E}_{\mathrm{R}}} \cdot \frac{1}{\sqrt{\mathrm{A}_{\mathrm{CP}}}} \\
\mathrm{A}_{\mathrm{CP}} & =24.5 \cdot \mathrm{h}_{\mathrm{c}}^{2}
\end{aligned}
$$

where, $\mathrm{C}_{\mathrm{f}}$, compliance value for the used test frame which equals to $0.000561 \mu \mathrm{m} / \mathrm{mN} ; E_{R}$, modulus of elasticity; $\beta$ and $\lambda$, correction factors which equal to 1.05 (Oliver and Pharr, 2004) and 1.1 (Hay et al., 2008), respectively; $\mathrm{A}_{\mathrm{cP}}$, the projected contact area $\left(\mu \mathrm{m}^{2}\right)$ as previously reported (Oliver and Pharr, 1992); $h_{c}$, the depth $(\mu \mathrm{m})$ as previously reported (Oliver and Pharr, 1992).

The E-modulus of the tested material $\left(\mathrm{E}_{m}\right)$ is then calculated with Equation (8).

$$
\frac{1}{E_{\mathrm{r}}}=\frac{1-v_{\mathrm{m}}^{2}}{\mathrm{E}_{\mathrm{m}}}+\frac{1-\nu_{\mathrm{i}}^{2}}{\mathrm{E}_{\mathrm{i}}}
$$

where, $\nu_{m}$, estimated value for the Poisson coefficient of the tested cement based material which equals to 0.3 ; $v_{\mathrm{i}}$, the Poisson 
coefficient of the diamond indenter which equals to $0.07 ; \mathrm{E}_{i}$, the E-modulus of the diamond indenter which equals to $1140 \mathrm{GPa}$.

The mechanical characteristics of the original cement paste and the $\mathrm{CaCO}_{3}$ precipitated in the crack were determined by indentation tests. Ten to fifteen indentations were performed per test sample and per phase.

The inner crack surface of the mature specimens (6 months cured) was also analyzed, yet indentation tests were not conducted for these samples. During the visual inspection and EDX analysis of mature specimens, FEI Quanta 200F SEM/EDX (Oregon, USA) was used. In order to analyze and identify the healing materials inside the crack, a sawn sample with the crack $(10 \times 30 \times 30 \mathrm{~mm})$ was further split through the crack into two pieces by using manual force. One of the surfaces was coated with carbon ( $\sim 15-35 \mathrm{~nm}$ thickness) and analyzed under SEM/EDX. The micrographs showing the inner crack surface of the mature specimens were taken at accelerating voltage of $15 \mathrm{kV}$ and a working distance of $8-9 \mathrm{~mm}$. The second piece was used for Fourier transform infrared spectroscopy (FTIR) analysis. The composition at a certain depth was the main interest, thus on the crack surface, an area of $1 \mathrm{~cm}^{2}(5 \times 20 \mathrm{~mm})$ was defined at a distance of $5 \mathrm{~mm}$ from the crack mouth and $2 \mathrm{~mm}$ from the reinforcement bar. The defined area was scraped by using a stainless steel spatula ( $5 \mathrm{~mm}$ width) and the pieces were collected $(<15 \mathrm{mg})$. Collected pieces were further ground into powder by using a mortar and pestle. A portion of the ground powder $(<5 \mathrm{mg})$ was chemically characterized by using Spectrum 100 FTIR (Perkim Elmer Inc, USA). Presented spectra were the result of 32 scans with a resolution of $4 \mathrm{~cm}^{-1}$ in the range of $4000-600 \mathrm{~cm}^{-1}$.

\section{Analytical Methods}

The VSS and TSS analysis were done according to the standard methods (APHA et al., 2012). Nitrate $\left(\mathrm{NO}_{3}^{-}\right)$and nitrite $\left(\mathrm{NO}_{2}^{-}\right)$ concentrations were measured via compact Metrohm 761 ion chromatography (IC) (Herisau, Switzerland). Statistical analyses were conducted using SigmaPlot 12.0 (Systat Software Inc., USA) to compare significant differences by means of One way ANOVA test $(p=0.05)$.

\section{RESULTS}

\section{Quality Assessment of the Culture}

The appearance of the harvested ACDC granules are given in Figures 1A,B. After the drying process, the ACDC granules shrink and their color became darker (Figures 1C,D). Based on the conducted solid analyses, the VSS concentration at steadystate operation was $5.5 \pm 0.2 \mathrm{~g} / \mathrm{L}$ and the TSS concentration was $7.8 \pm 0.4 \mathrm{~g} / \mathrm{L}$.

At steady operation, ACDC:VSS ratio (the amount of granulated culture) in the system was more than $90 \%$. The only nitrogen $(\mathrm{N})$ source fed to the system was $\mathrm{NO}_{3}-\mathrm{N}$. When the influent $\mathrm{NO}_{3}-\mathrm{N}$ concentration $(280 \mathrm{mg} / \mathrm{L}$, Table 1$)$, the volume exchange ratio $(50 \%)$ and the residual $\mathrm{NOx}-\mathrm{N}(\sim 32 \mathrm{mg} / \mathrm{L}$, Figure 2) concentration at the end of a cycle during steady operation were taken into consideration, one can calculate the denitrification performance of ACDC for both anoxic and aerobic periods. Regular NOx-N measurements revealed that at the end of anoxic period $69 \%$ of the total nitrogen (TN) was consumed. Following kinetic NOx-N measurements in aerobic period (dissolved oxygen $\sim 6 \mathrm{mg} / \mathrm{L}$ ), it appeared that there was simultaneous nitrification and denitrification. Results indicated that $34 \%$ of the TN was consumed through simultaneous denitrification occurring in aerobic period (Figure 2).

\section{Self-healing Performance of Microbial Mortars Containing ACDC Culture}

The addition of ACDC and nutrients [concrete admixtures $\mathrm{Ca}(\mathrm{HCOO})_{2}$ and $\left.\mathrm{Ca}\left(\mathrm{NO}_{3}\right)_{2}\right]$ significantly improved the selfhealing potential of mortar specimens (Figures 3A, 4). At the end of 28 days immersion in water, self-healing performances

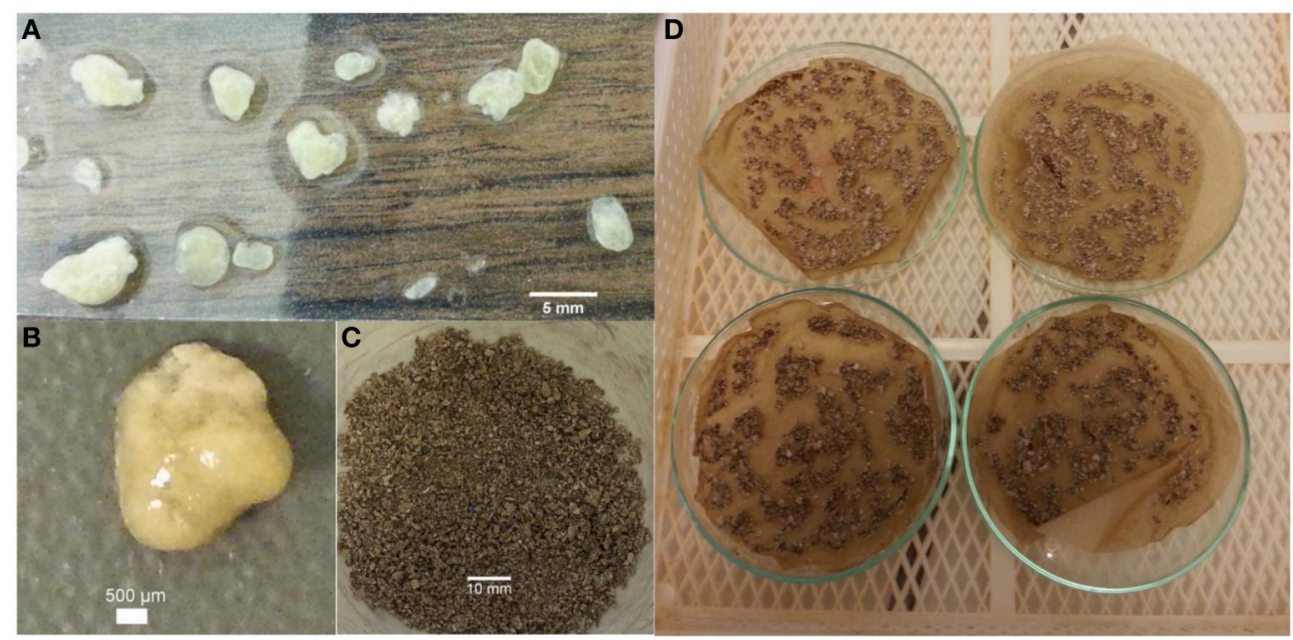

FIGURE 1 | Appearance of the harvested ACDC granules (A,B) wet; (C,D) after drying. 
of the mortars containing $0.5 \%$ ACDC were similar to the ones containing $1 \%$ ACDC. Cracks up to $500 \mu \mathrm{m}$ crack width were closed more than $90 \%$ (Figure 3A). The limit for the autogenous healing was recorded as 200 and $250 \mu \mathrm{m}$ for reference specimen and abiotic control specimen, respectively (Figure 3A). Crack closure performances of the reference specimens sharply decreased when the initial crack widths were more than $200 \mu \mathrm{m}$. Among the control specimens, the ones containing nutrients (abiotic control) showed significantly better healing performance and could close cracks up to $250 \mu \mathrm{m}$ (Figure 3A).

Capillary sorption tests revealed that microbial specimens could have a better water tightness than the control specimens (Figure 3B). The capillary sorption tests were conducted around the cracks with $432 \pm 21 \mu \mathrm{m}$ crack width for the specimens cracked at 28 days and healed for 28 days. Reference and

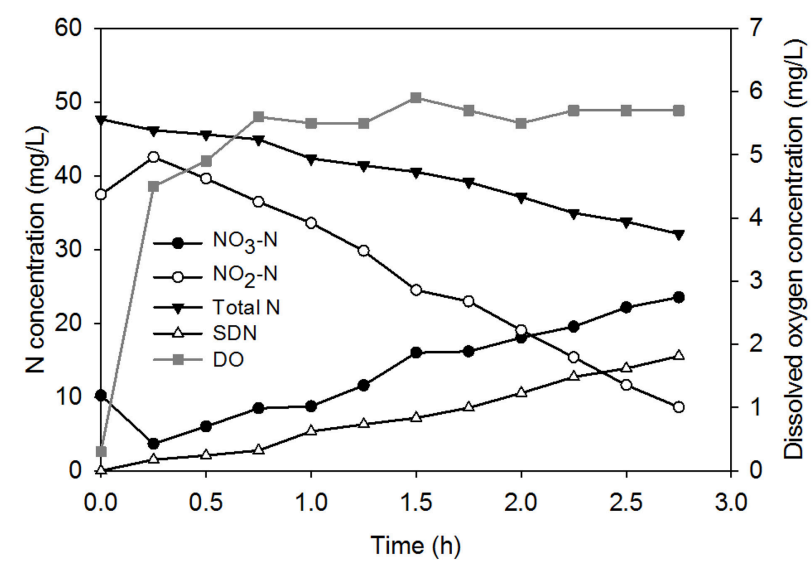

FIGURE 2 | Kinetic NOx-N measurements during the aerobic period of an arbitrarily chosen SBR cycle (SDN, simultaneous denitrification; DO, dissolved oxygen concentration). abiotic control specimens were found to be similar in terms of water tightness. After the 28 days healing period, the microbial specimens containing 1 and $0.5 \%$ ACDC (w/w cement) absorbed $68 \pm 5 \%$ and $61 \pm 4 \%$ less water around the crack $(\sim 432 \pm 21 \mu \mathrm{m}$ initial crack width) than the reference specimens, respectively (Figure 3B). Different from the crack closure performances, in terms of water tightness, there was a slight but significant difference between the microbial specimens containing two different amounts of ACDC. Mortar specimens containing 1\% ACDC absorbed $18 \pm 8 \%$ less water than the mortar specimens containing 0.5\% ACDC (Figure 3B).

\section{Nutrient Availability and the Microbial Activity during Incubation}

One of the components of microbial self-healing concrete is the nutrients that initiate and maintain the bacterial activity. Therefore, availability of the nutrients for the bacteria is important. The results of the abiotic control are representative for the NOx-N passed from mortar to the solution, thus indicates the nutrient availability (Figure 5A). Based on the results, 14\% of the $\mathrm{NO}_{3}-\mathrm{N}$ in a mortar specimen became available for microbial use (See Supplementary Material for calculations). Additionally, one can confirm the bacterial activity by the evolution of the abundance of nitrate or formate in solution. Weekly measurements of the NOx-N revealed that $92 \pm 2 \%$ of the available $\mathrm{NO}_{3}-\mathrm{N}$ was consumed by the ACDC culture during the crack closure process (Figure 5A). Bacterial activity $\left(\mathrm{NO}_{3}^{-}\right.$ reduction rate) significantly improved after $\mathrm{pH}$ decreased below 10 (Figures 5A,B).

\section{Mechanical Properties of the Healing Material Inside the Crack}

The abundant formation on the inner crack surface of the microbial specimen was a white colored precipitate (Figure 6A). Visual inspection revealed that observed white precipitates
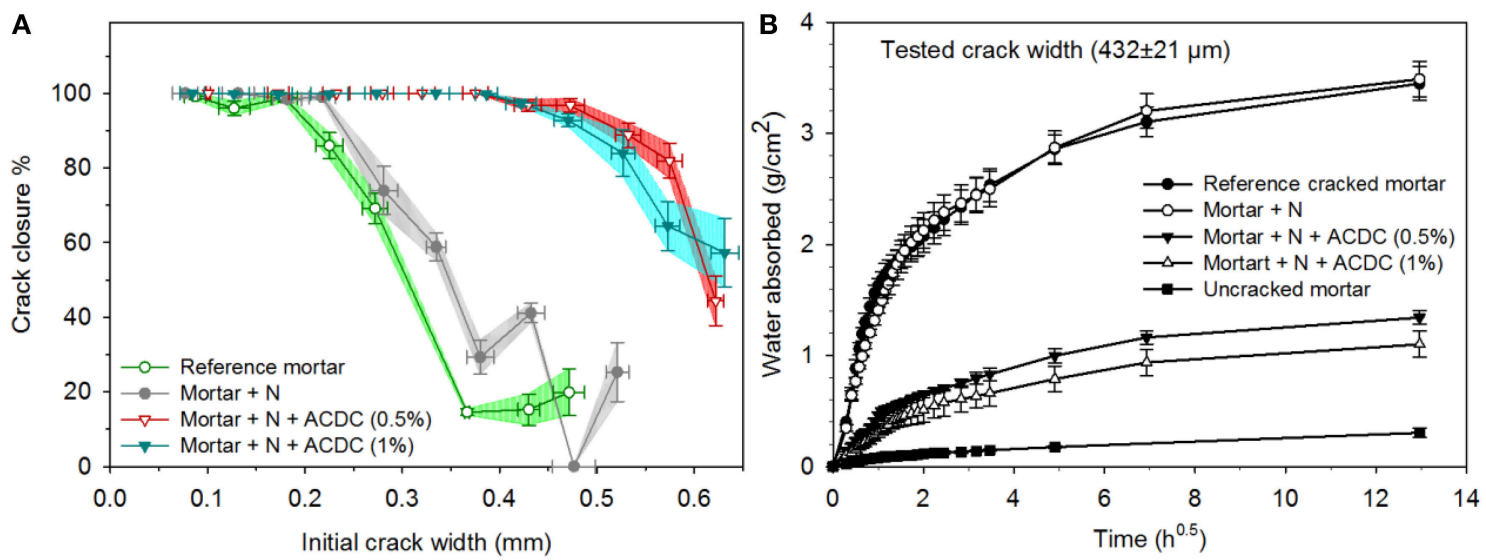

FIGURE 3 | The enhanced self-healing performance of the 28 days old microbial specimens over the control specimens (A) the crack closure performance (horizontal error bars represent the standard deviation, crack widths were grouped with $50 \mu \mathrm{m}$ intervals, vertical error bars represent the standard error of the mean, $n \geq 5)(B)$ capillary sorption around the crack zone of the healed specimens [N: Nutrients $-2 \% \mathrm{Ca}(\mathrm{HCOO})_{2}+3 \%$ $\mathrm{Ca}\left(\mathrm{NO}_{3}\right)_{2}$; the error bars represent the standard deviation, $n=3$. 


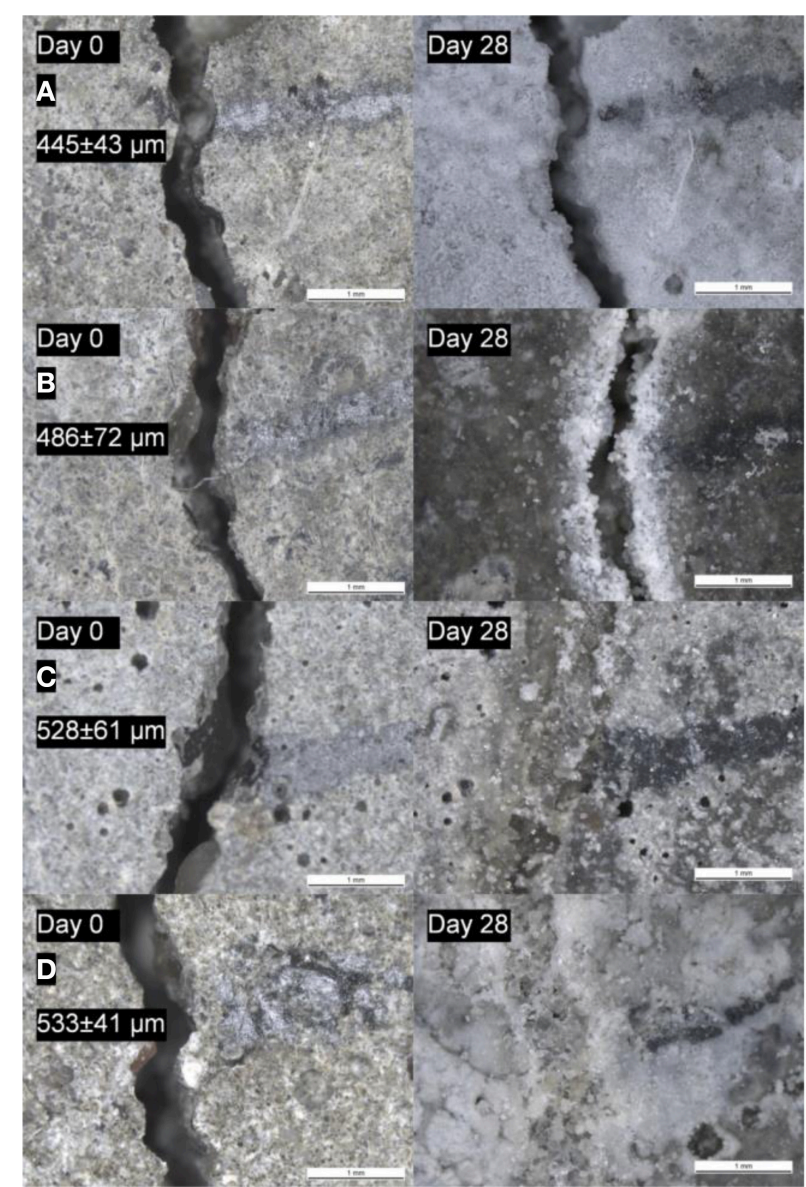

FIGURE 4 | The micrographs showing the initial (before incubation) and the final (after 28 days incubation) appearance of the cracks of the 28 days old specimens $(A)$ reference specimen $(B)$ abiotic control (reference $+5 \%$ nutrients) (C) specimen with $0.5 \%$ ACDC and $5 \%$ nutrients (D) specimen with 1\% ACDC and 5\% nutrients [N: Nutrients $2 \% \mathrm{Ca}(\mathrm{HCOO})_{2}+3 \% \mathrm{Ca}\left(\mathrm{NO}_{3}\right)_{2}$; weight percentages are in terms of cement weight].

were biochemically formed $\mathrm{CaCO}_{3}$ (in the form of calcite) (Figures 6C,D). Moreover, a portion of the ACDC granule ( $\sim 40 \mu \mathrm{m}$ wide) and the $\mathrm{CaCO}_{3}$ formation around the cluster could be visualized during the SEM analysis (Figure 6D). Additionally, individual bacterial remains were also found on precipitates (Figure 6C).

In addition to visual analysis, mechanical properties of the calcite crystals were quantified through indentation tests (Figure 7). Martens hardness was measured and based on the available data approximate E-modulus values were calculated. The Martens hardness values of $2.1 \pm 0.2 \mathrm{GPa}$ and $2.1 \pm$ $0.7 \mathrm{GPa}$ were achieved from the tested $\mathrm{CaCO}_{3}$ minerals in reference and microbial specimens, respectively (Figure 8A). The variation of hardness values for $\mathrm{CaCO}_{3}$ minerals were higher in microbial specimens than the reference specimens, yet they did not significantly differ among the specimens (Figure 8A). Further visual inspection of the indentation points revealed that on some of the minerals nano-cracks occurred under indentation

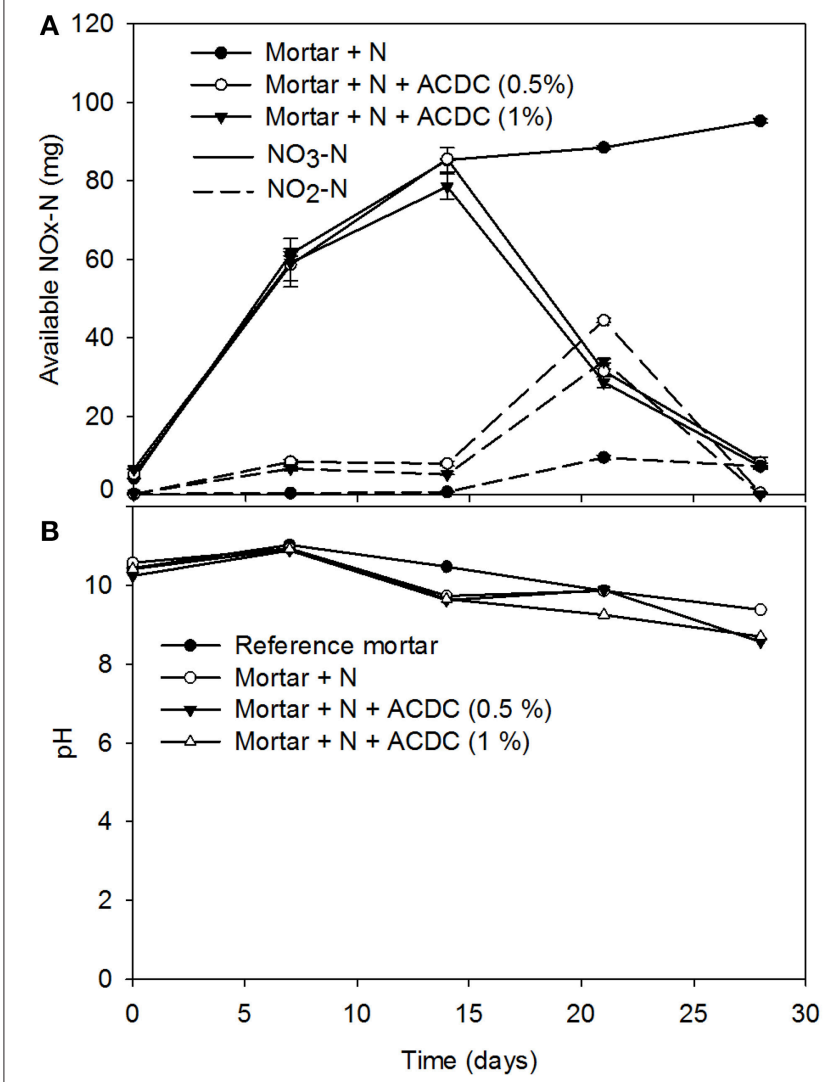

FIGURE 5 | Evolution of the available NOx-N in the bulk solutions during the 28 days incubation of the 28 days old specimens and the $\mathrm{pH}$ of the solution (A) mass of the available NOx-N (B) the pH change [N: Nutrients $-2 \% \mathrm{Ca}(\mathrm{HCOO})_{2}+3 \% \mathrm{Ca}\left(\mathrm{NO}_{3}\right)_{2} ; n=3$, error bars represent the standard deviation].

load (See Supplementary Figure 3). These observed cracks were not particular for a certain type of specimen and observed in both cases. Following indentation tests, sampling points and the different layers were visualized. Indentation measurements were also conducted on hydrated cement paste. Martens hardness values of $1.2 \pm 0.3 \mathrm{GPa}$ and $1.3 \pm 0.7$ were obtained for the hydrated cement paste in reference and microbial samples, respectively (Figure $\mathbf{8 A}$ ).

E-modulus values for the tested $\mathrm{CaCO}_{3}$ minerals were calculated as $54 \pm 10 \mathrm{GPa}$ and $49 \pm 8 \mathrm{GPa}$ from the data obtained whilst testing reference and microbial samples, respectively (Figure 8B). The E-modulus values for the hydrated cement paste were $35 \pm 9 \mathrm{GPa}$ and $26 \pm 8 \mathrm{GPa}$ for reference and microbial specimens (Figure 8B).

\section{Chemical Characterization of the Healing Material}

In addition to the SEM imaging, the elemental composition of minerals was analyzed by using EDX spectroscopy. Visualized minerals were composed of $\mathrm{Ca}, \mathrm{C}$, and $\mathrm{O}$ elements which indicated that the minerals were most probably $\mathrm{CaCO}_{3}$ (Figure 6B). In order to confirm the EDX results, powders 

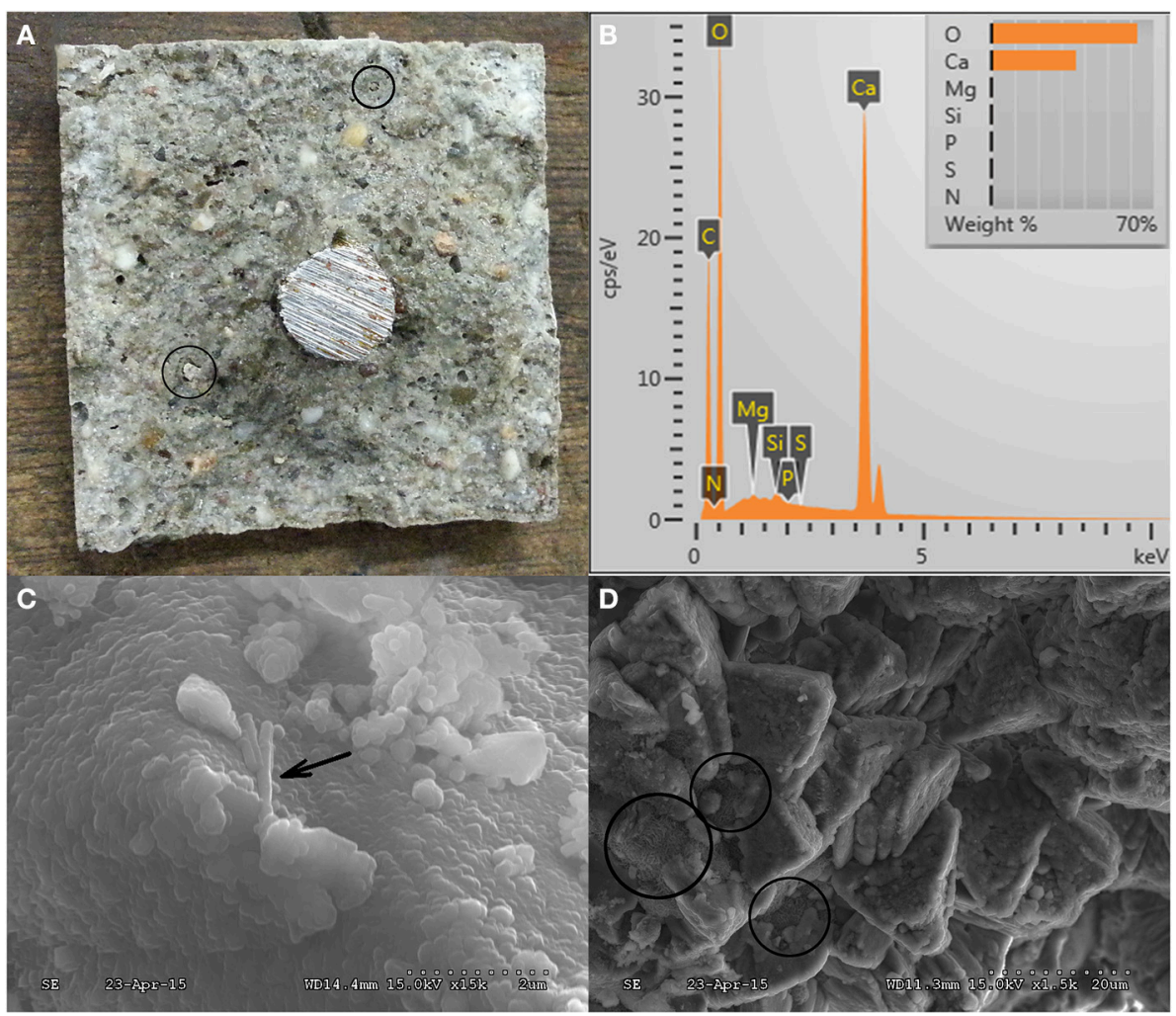

FIGURE 6 | Micrographs showing the inner crack surface of the 28 days old microbial specimen and the EDX results (A) inner crack surface appearance of microbial specimen after splitting (B) chemical composition of the minerals around the bacteria (C,D) SEM micrographs of the inner crack surface (" $\nearrow$ " indicates the individual bacterial remains, "o" indicates the calcified ACDC cluster).

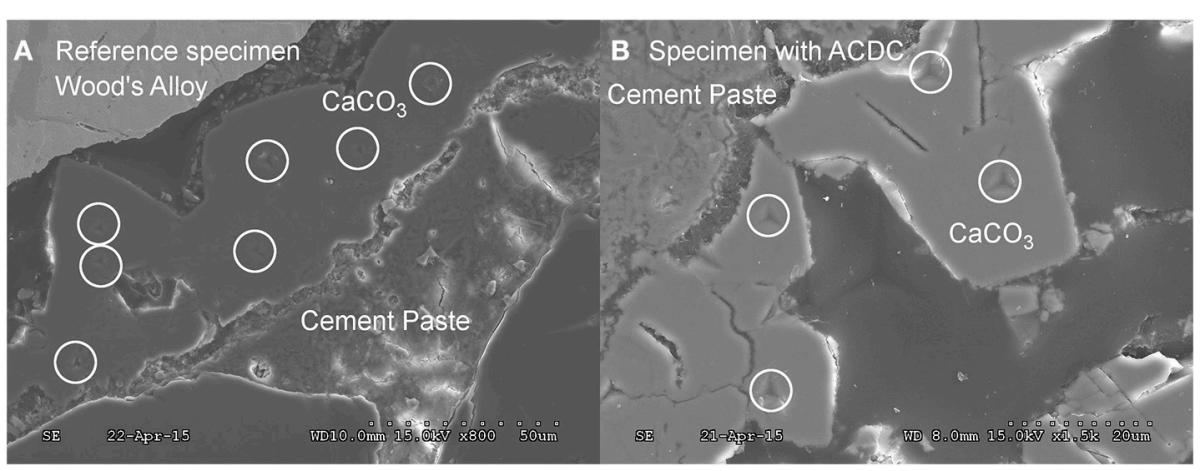

FIGURE 7 | SEM micrographs showing the indentation points whilst mechanical testing of the calcite (A) calcite formed in reference specimen (B) calcite formed in microbial specimen (0.5\% ACDC). "o" indicates the points analyzed during indentation. Please refer to Supplementary Figure 3 for higher resolution on indentation.

were collected from the counter face of the crack surface and chemically characterized via FTIR analysis. The information collected from both analyses revealed that the visualized and tested minerals inside the crack of microbial specimens were $\mathrm{CaCO}_{3}$ (Figures 6B, 9). In addition to calcite $(2513,1793$, 1412,873 , and $\left.713 \mathrm{~cm}^{-1}\right)$, aragonite $\left(696 \mathrm{~cm}^{-1}\right)$, ettringite $\left(1163 \mathrm{~cm}^{-1}\right)$, bassanite $\left(1083 \mathrm{~cm}^{-1}\right), \mathrm{C}_{2} \mathrm{~S}\left(873 \mathrm{~cm}^{-1}\right)$, C-S-H (1052, 1980, and $\left.2163 \mathrm{~cm}^{-1}\right)$, and portlandite $\left(3649 \mathrm{~cm}^{-1}\right)$ were found in the collected powder samples (Hughes et al., 1995; Mollah et al., 2000; Yu et al., 2004; Trezza et al., 2007) (Figure 9). In the powders collected from control specimens, cement and its hydration products were as abundant as the forms of $\mathrm{CaCO}_{3}$ (Figure 9) Contrarily, in the powder collected from the microbial specimens, different forms of $\mathrm{CaCO}_{3}$ were the dominant compounds (Figure 9). 


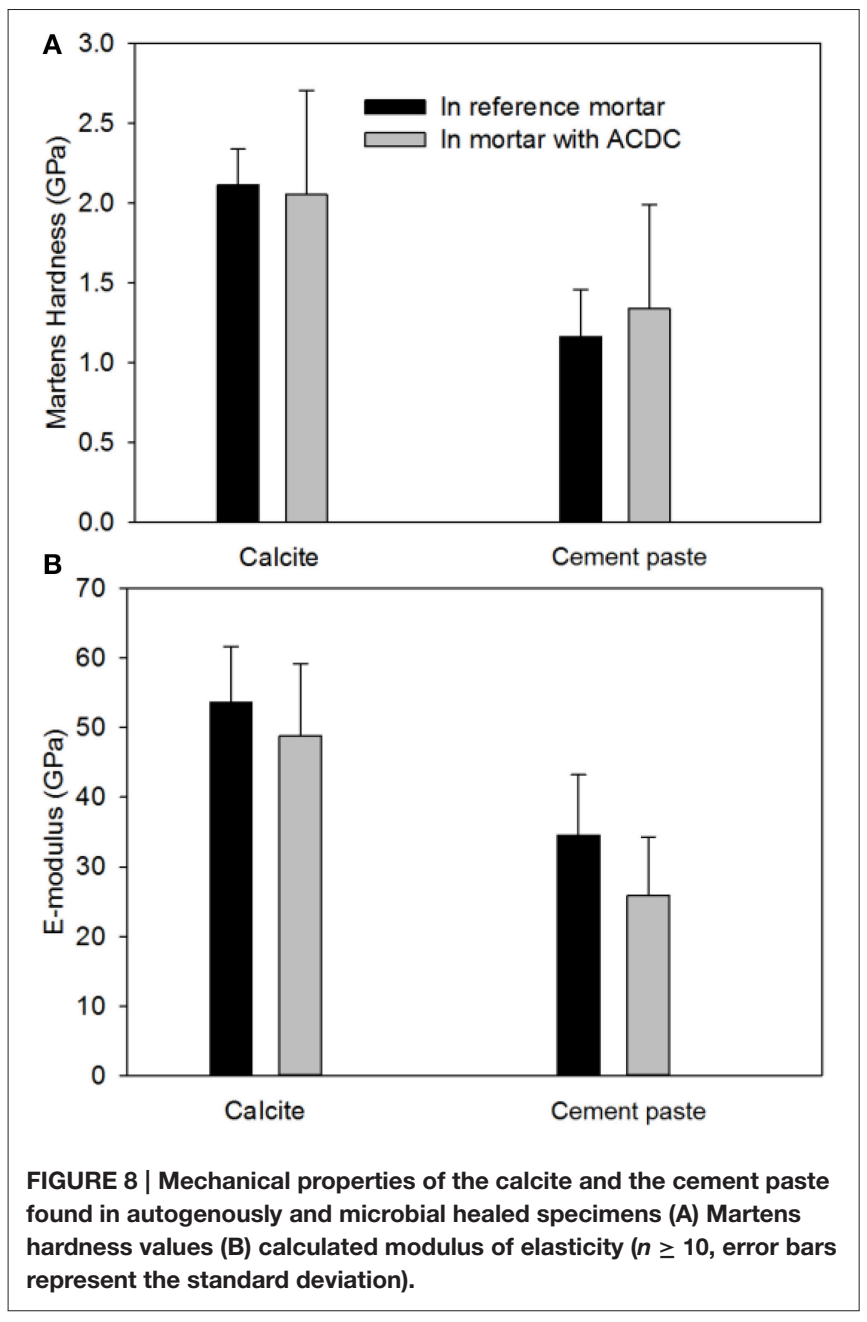

\section{Effect of Age on Microbial Crack Healing}

Autogenous healing performance of the control specimens significantly decreased when the cracks formed after 6 months curing instead of 28 days curing (Figures 10A, 11). Based on the data obtained for the investigated crack width range (100$500 \mu \mathrm{m}$ ), autogenous healing performance after 6 months was recorded as $86 \pm 8 \%$ for $135 \mu \mathrm{m}$ crack width and gradually decreased with an increasing initial crack width (Figure 10A). Although, a noticeable decrease also appeared in microbial samples, $\sim 90 \%$ crack closure was achieved for the cracks up to $400 \mu \mathrm{m}$ crack width (Figure 10A). The closure performance of the cracks larger than $400 \mu \mathrm{m}$ was still more than $70 \%$ (Figures 10A, 11).

Capillary sorption tests revealed that microbial specimens could have a better water tightness than the control specimens (Figure 10B). The capillary sorption tests were conducted around the cracks with $345 \pm 23 \mu \mathrm{m}$ crack width for 6 month old specimens. Reference and abiotic control specimens were found to be similar in terms of water tightness (Figure 10B). After the 28 days healing period, the microbial specimens containing 1 and $0.5 \%$ ACDC (w/w cement) absorbed $54 \pm 8 \%$ and $49 \pm 6$ less water around the crack $(\sim 345 \pm 23 \mu \mathrm{m}$ initial crack width) than the reference specimens, respectively (Figure 10B). Among the microbial specimens, no significant differences were observed in terms of water tightness.

The inner crack surface was visually explored in both control and microbial specimens. During the visual inspection of microbial specimens, a significant amount of biochemically formed $\mathrm{CaCO}_{3}$ minerals and calcified bacteria were found (Figures 12C,D). On the inner crack surface of the control specimens, $\mathrm{CaCO}_{3}$ and $\mathrm{C}-\mathrm{S}-\mathrm{H}$ were found (Figures 12A,B). Especially in the EDX spectrums obtained on the inner crack surface of control specimens, Si peaks were significant which was confirming the abundance of C-S-H (Figures 12A,B). Differently, the $\mathrm{C}$ and $\mathrm{O}$ peaks were remarkable in microbial specimens indicating the abundance of $\mathrm{CaCO}_{3}$ (Figures 12C,D). Moreover, some ettringite shaped formations were found in control specimens (Figures 12A,B).

\section{DISCUSSION}

\section{Quality of the ACDC}

The denitrification performance achieved under aerobic conditions was an indication of a denitrifying core. The major reason of the denitrifying activity was the size of the granules that prevented oxygen diffusion creating an anoxic zone at the core (Erşan and Erguder, 2013). The anoxic/aerobic operation enhanced the enrichment of nitrate reducing bacteria at the core of the granules which was consistent with the previous studies (Wan et al., 2009; Erşan and Erguder, 2013). In addition to the denitrification, nitrification was also observed in the aerobic period which indicated the presence of nitrite oxidizing bacteria near the surface of the granules. This type of placement was an indication for the aimed layered structure. The inorganic content of the ACDC was $30 \%$ which was higher than the content of a typical granular biomass (Wan et al., 2009; Erşan and Erguder, 2013). This was due to the feed composition that was enriched in terms of $\mathrm{Ca}^{2+}\left(0.10 \mathrm{~g} / \mathrm{L} \mathrm{Ca}^{2+}\right)$ compared to the synthetic feed composition used (contains $0.03 \mathrm{~g} / \mathrm{L} \mathrm{Ca}^{2+}$ ) in the reference study (Erşan and Erguder, 2013). The VSS/TSS ratio of 0.6 was reported for the anaerobic granules cultivated by using $0.15 \mathrm{~g} / \mathrm{L}$ $\mathrm{Ca}^{2+}$ and increased to 0.7 when the influent $\mathrm{Ca}^{2+}$ concentration was $0.01 \mathrm{~g} / \mathrm{L}$ (Yu et al., 2001). Previous studies also showed that the $\mathrm{Ca}^{2+}$ related precipitates mainly form the inorganic content of the granular biomass (Ren et al., 2008). Therefore, for ACDC, the major constituents of the inorganic content was expected to be $\mathrm{CaCO}_{3}$ and $\mathrm{Ca}\left(\mathrm{PO}_{4}\right)_{3}$ which also act as a protective layer for the nitrate reducers at the core.

\section{Crack Closure and Functionality Regain}

Autogenous healing limits of the 28 days old mortar specimens were recorded as 200 and $250 \mu \mathrm{m}$ for reference and abiotic control, respectively. Previous studies reported comparable results for plain mortar specimens under similar incubation conditions (immersion in tap water) (Van Tittelboom and De Belie, 2013; Wang et al., 2014c; Silva et al., 2015b). The major reasons of autogenous healing were investigated in many studies and listed as (i) swelling of the crack walls, (ii) further hydration of unhydrated cement paste, (iii) blockage due to the 


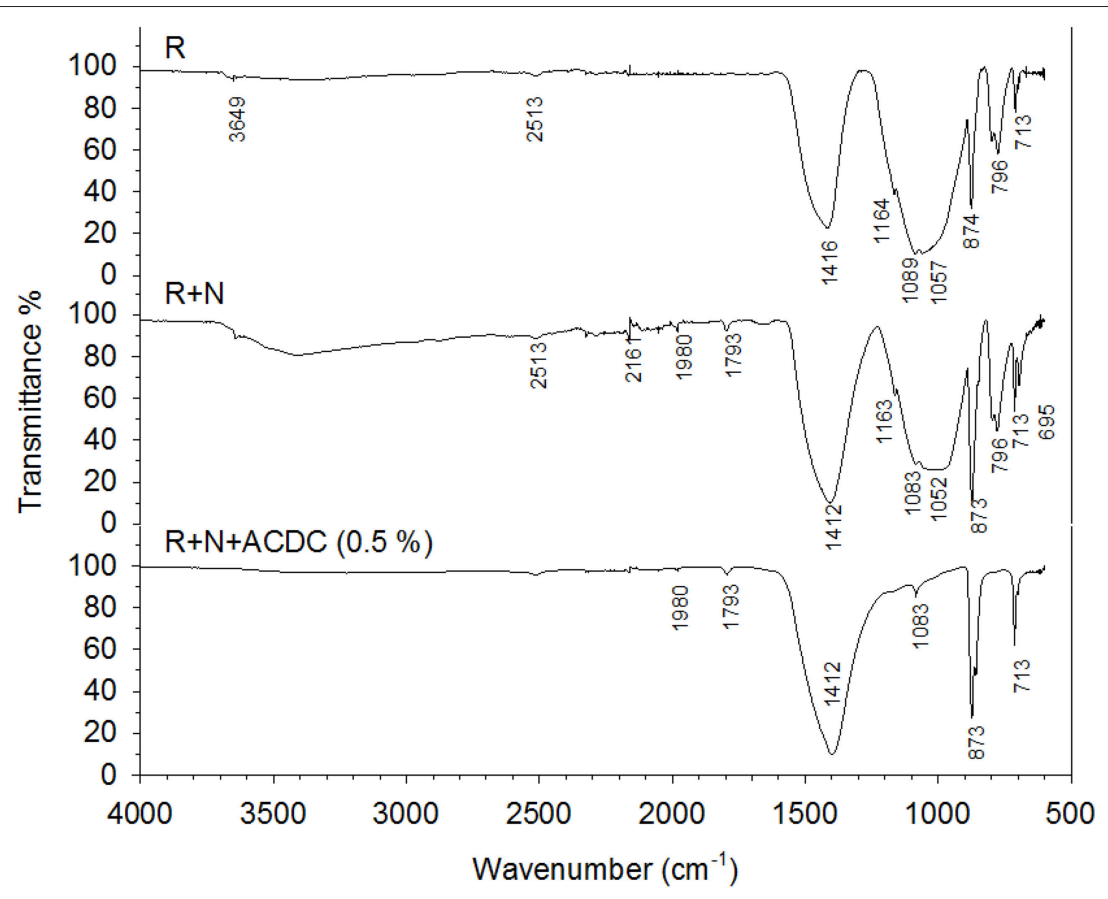

FIGURE 9 | FTIR spectra of the healing materials collected from the inner crack surfaces of 28 days old specimens [R, Reference; N, Nutrients - $2 \%$ $\mathrm{Ca}(\mathrm{HCOO})_{2}+3 \% \mathrm{Ca}\left(\mathrm{NO}_{3}\right)_{2} ; 5 \mathrm{~mm}<$ sampling depth $\left.<13 \mathrm{~mm}\right]$.

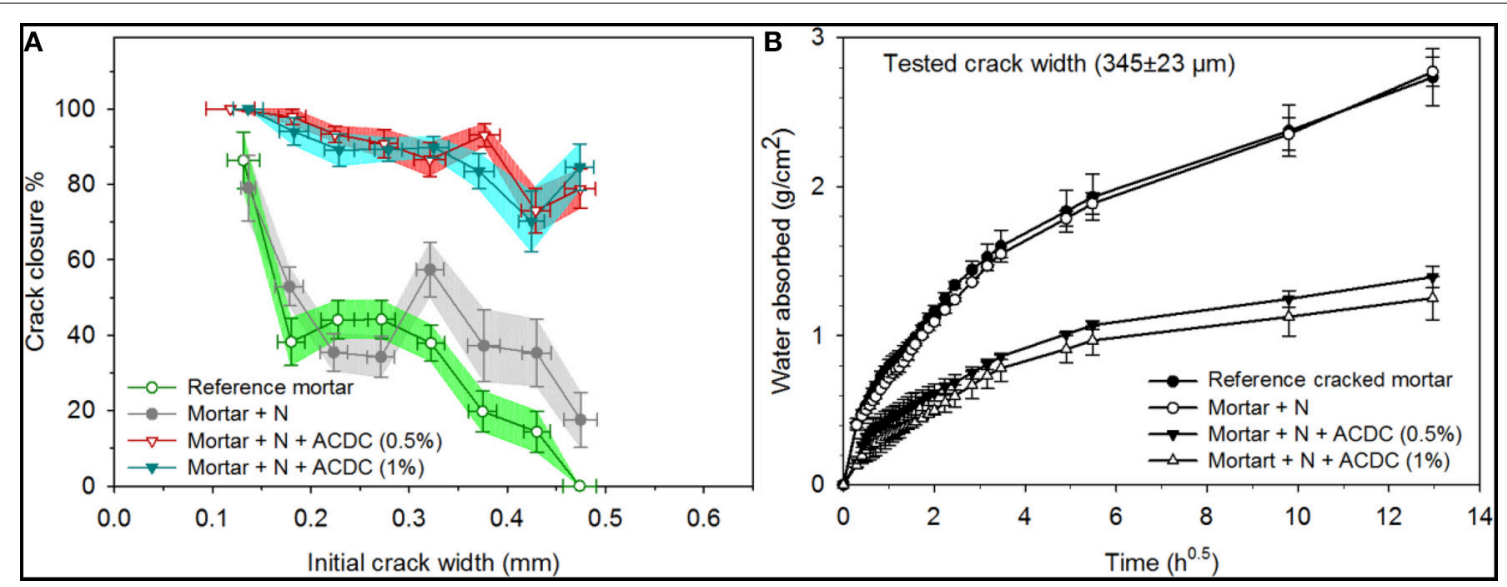

FIGURE 10 | The enhanced self-healing performance of the 6 months old microbial specimens over the control specimens (A) the crack closure performance (horizontal error bars represent the standard deviation, crack widths were grouped with $50 \mu \mathrm{m}$ intervals, vertical error bars represent the standard error of the mean, $n \geq 5)(B)$ capillary sorption around the crack zone of the healed specimens [N: Nutrients $-2 \% \mathrm{Ca}(\mathrm{HCOO})_{2}+3 \%$ $\mathrm{Ca}\left(\mathrm{NO}_{3}\right)_{2}$; the error bars represent the standard deviation, $n=3$ ].

sedimentation of fractured pieces, (iv) formation of $\mathrm{CaCO}_{3}$ at the crack mouth due to the carbonation of portlandite (Edvardsen, 1999; Van Tittelboom and De Belie, 2013).

Among the control specimens, abiotic control specimens showed slightly higher autogenous healing compared to the reference specimens. This enhanced performance could be due to the positive effect of admixtures on $\mathrm{CaCO}_{3}$ precipitation. $\mathrm{CaCO}_{3}$ precipitation is highly influenced by the $\mathrm{pH}$, the $\mathrm{Ca}^{2+}$ concentration, the dissolved inorganic carbon concentration and the presence of nucleation sites. The abiotic control had higher $\mathrm{Ca}^{2+}$ concentration due to the addition of $\mathrm{Ca}(\mathrm{HCOO})_{2}$ and $\mathrm{Ca}\left(\mathrm{NO}_{3}\right)_{2}$ which might improve the $\mathrm{CaCO}_{3}$ precipitation and thus the crack closure performance of the abiotic control. Similar improvement was observed in previous studies when the $\mathrm{Ca}^{2+}$ concentration was increased (Wang et al., 2012a, 2014c).

The autogenous healing performance significantly decreased when the cracks formed in mature specimens (6 months old). It was not possible to effectively close the $150 \mu \mathrm{m}$ crack width 


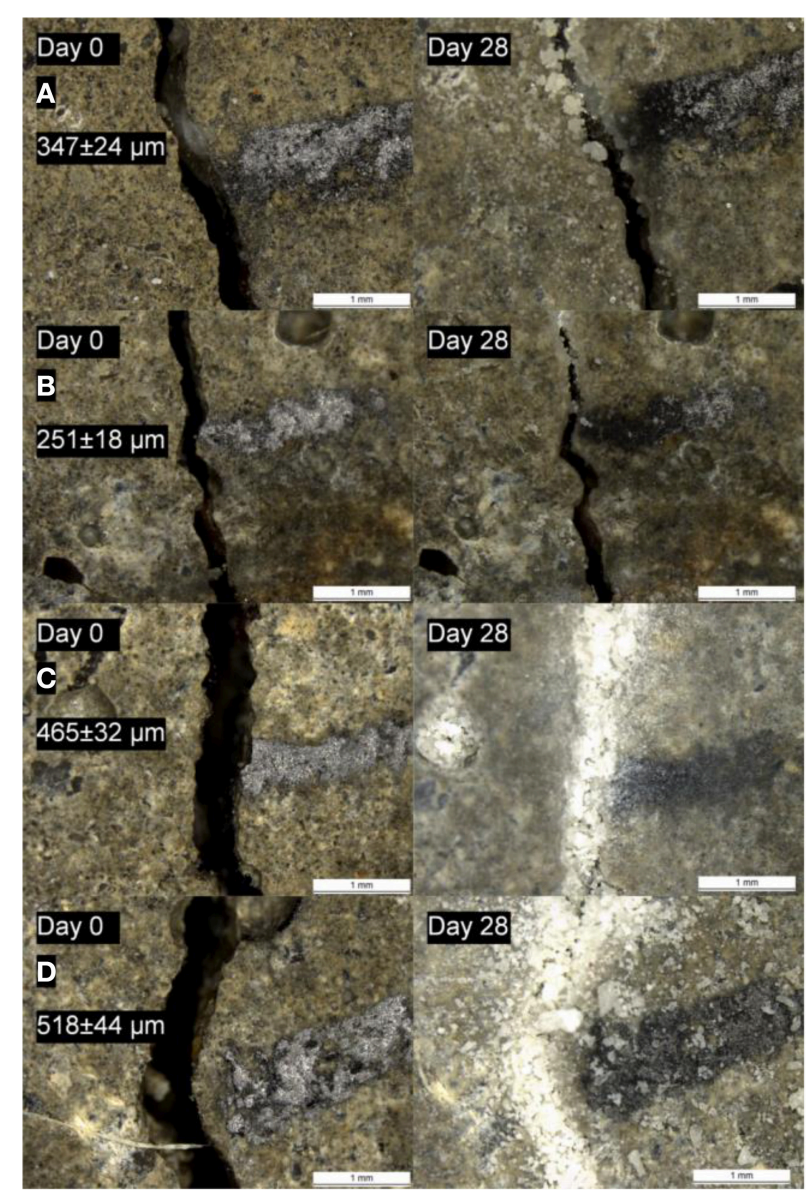

FIGURE 11 | The micrographs showing the initial (before incubation) and the final (after 28 days incubation) appearance of the cracks of the 6 months old specimens (A) reference specimen; (B) abiotic control (reference $+5 \%$ nutrients); (C) specimen with $0.5 \%$ ACDC and 5\% nutrients; (D) specimen with 1\% ACDC and 5\% nutrients [Nutrients $2 \% \mathrm{Ca}(\mathrm{HCOO})_{2}+3 \% \mathrm{Ca}\left(\mathrm{NO}_{3}\right)_{2}$; weight percentages are in terms of cement weight].

through autogenous healing. Yang et al. (2009), also suggested that the crack widths on mature specimens should be kept less than $150 \mu \mathrm{m}$ which is consistent with our observation. These results indicated that the hydration of the unhydrated cement in pre-mature samples has significant influence on autogenous healing potential.

Unlike the abiotic control, microbial specimens considerably improved the self-healing potential for both early age and mature cracks. Although it is known that the spores can survive in extreme environments for a long time (Harwood and Cutting, 1990), the self-healing performance of a mature microbial concrete was always a concern. In this study, the crack closure performance of a mature microbial mortar was more than $90 \%$ up to a crack width of $400 \mu \mathrm{m}$. The limit was three to four times higher than the autogenous healing limit of a mature mortar specimen. Therefore, it can be said that microbial mortars offer self-healing not only for early age cracks but also for the mature cracks.
During the incubation period of 28 days old mortar specimens, available NOx-N concentrations were measured. The consumption of the available $\mathrm{NO}_{3}-\mathrm{N}$ confirmed that the enhanced crack closure performance observed in microbial specimens was due to the microbial activity. Bacterial remains on calcite minerals and mineral formation around the ACDC agglomerates also evidenced the self-healing through MICP.

Crack closure achieved through MICP after 28 days treatment period were comparable with the previously reported microbial self-healing results (Wiktor and Jonkers, 2011; Wang et al., 2014b,c; Silva et al., 2015b). Microbial self-healing studies where ureolytic spores were used as bacterial healing agent reported closure of cracks up to $350-400 \mu \mathrm{m}$ crack in 28 days (Wang et al., 2014a; Silva et al., 2015b). By incorporating hydrogel protected ureolytic bacterial spores in mortar, more than $80 \%$ crack closure up to $485 \mu \mathrm{m}$ crack width was achieved in 28 days (Wang et al., 2014b). Wiktor and Jonkers (Wiktor and Jonkers, 2011) reported complete crack healing up to $460 \mu \mathrm{m}$ in 100 days by using expanded clay particles loaded with aerobicbacterial spores as self-healing additive. The mentioned studies were conducted by using axenic bacterial spores. Incorporation of ACDC appears to give slightly better performance in terms of the healable crack width range and the healing rate. To our knowledge, the only reported trial of non-axenic culture as bacterial agent for microbial self-healing concrete was done with the Cyclic EnRiched Ureolytic Powder (CERUP) (Silva et al., 2015b). Similar to ACDC, CERUP was reported as a selfprotected non-axenic culture (Erşan et al., 2015c; Silva et al., 2015b). By incorporating 1\% CERUP (CDW/weight cement), the self-healing limit of the mortar specimens could be extended to $450 \mu \mathrm{m}$ crack width (Silva et al., 2015b). In this study by incorporating 1\% ACDC (CDW/weight cement) crack closure up to $500 \mu \mathrm{m}$ was achieved in the same healing period which is comparable with the reported performance of microbial mortar containing CERUP.

Visual crack closure should always be coupled with other quantification methods to further assess the self-healing performance of mortar specimens (Palin et al., 2015). For example, functionality regain is one of the major interests in self-healing studies (Reinhardt and Jooss, 2003; Van Tittelboom et al., 2011; Li and Herbert, 2012; Wang et al., 2012a,b). So far, strength and water tightness are the common properties being investigated to quantify self-healing efficiency in many studies (Bang et al., 2001; Ramachandran et al., 2001; Van Tittelboom et al., 2011; Li and Herbert, 2012). Considering the initial average crack widths in this study (between 200 and $400 \mu \mathrm{m}$ ), it can be said that significant strength regain is unlikely. The major reason is; the amount of $\mathrm{CaCO}_{3}$ produced from the available nutrients was not enough to fill such large cracks and provide strength regain. Since the microbial activity could be followed in this study, one can roughly calculate how much of the crack volume could be completely filled. As results indicated, 14\% ( $102.7 \mathrm{mg}$ ) of the $\mathrm{NO}_{3}-\mathrm{N}$ in a mortar specimen $(722 \mathrm{mg}$ ) became available for microbial consumption and $91 \%(93.5 \mathrm{mg})$ of it was reduced by the bacteria at the end of 28 days. In a previous study, the $\mathrm{CaCO}_{3}$ precipitation yield of non-axenic cultures were reported as $12.7 \mathrm{~g} \mathrm{CaCO}_{3} / \mathrm{g} \mathrm{NO}_{3}-\mathrm{N}$ when $\mathrm{Ca}\left(\mathrm{NO}_{3}\right)_{2}$ and 


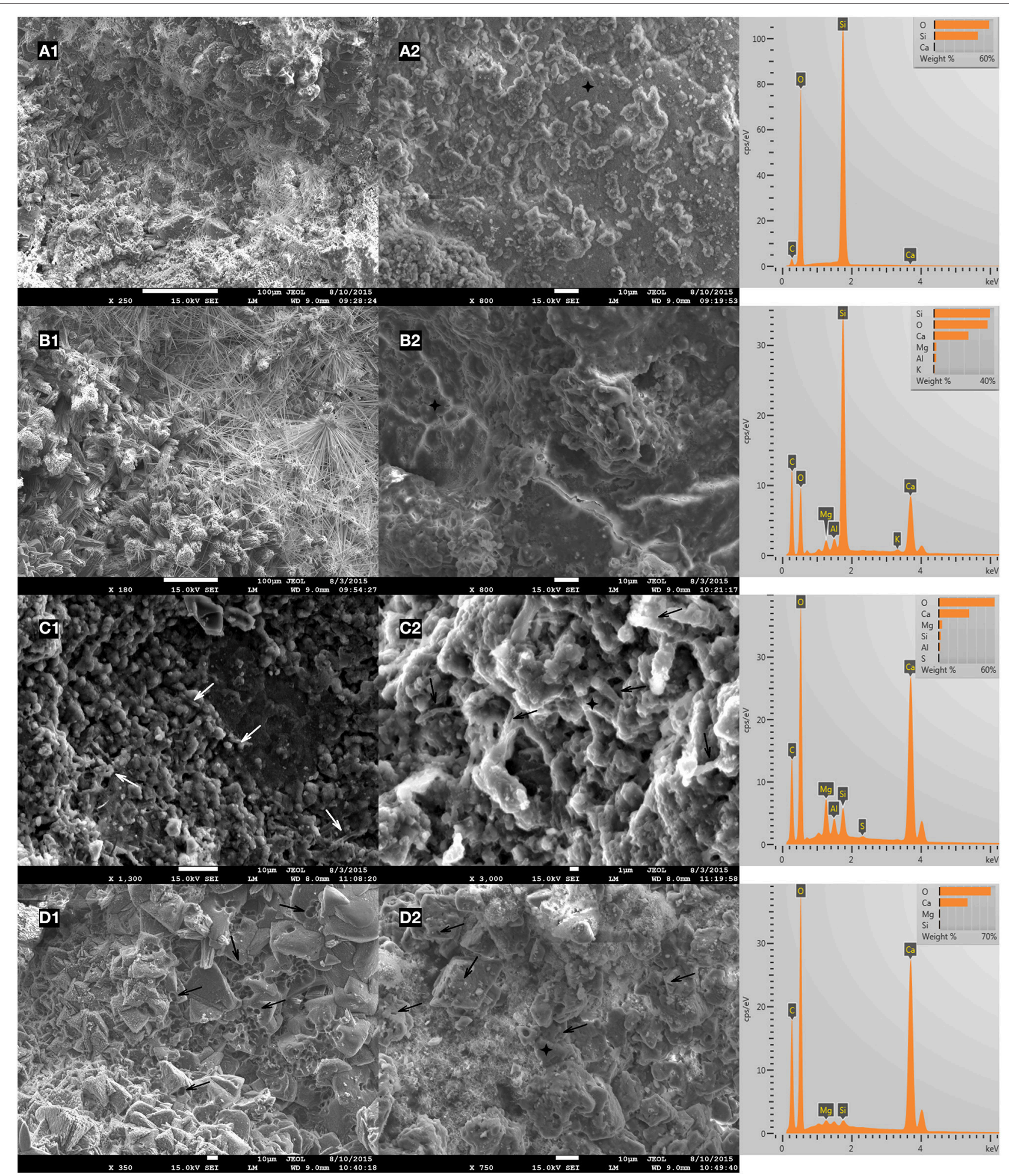

FIGURE 12 | Representative SEM micrographs and EDX analysis of the dominant healing material on the inner crack surface of 6 months old specimens after 28 days of healing (A1,A2) reference mortar; (B1,B2) abiotic control (reference $+5 \%$ nutrients); (C1,C2) mortar containing $0.5 \%$ ACDC and $5 \%$ nutrients; (D1,D2) mortar containing $1 \% \mathrm{ACDC}$ and $5 \%$ nutrient [Nutrients $-2 \% \mathrm{Ca}(\mathrm{HCOO})_{2}+3 \% \mathrm{Ca}\left(\mathrm{NO}_{3}\right)_{2}$; weight percentages are in terms of cement weight; " $\nearrow$ " indicates the calcified bacterial remains; "+" indicates the points analyzed via EDX]. 
$\mathrm{NaHCOO}$ were used as nutrients (Erşan et al., 2015a). Based on the reported precipitation yield, the $\mathrm{NO}_{3}^{-}$reduction occurred leads to precipitation of $\sim 1.2 \mathrm{~g} \mathrm{CaCO}_{3}$. Major form of the $\mathrm{CaCO}_{3}$ sealing the cracks was calcite and the density of calcite is $2.7 \mathrm{~g} / \mathrm{cm}^{3}$. Therefore, the amount of $\mathrm{CaCO}_{3}$ produced in this study was enough to fill approximately $440 \mathrm{~mm}^{3}$ crack volume. The dimensions of the each specimen were $30 \times 30 \times 360 \mathrm{~mm}$. The initial average crack width of the 28 days old microbial specimen (containing $0.5 \%$ ACDC) was $400 \pm 10 \mu \mathrm{m}$ and it had 4 cracks on the surface. Therefore, one can roughly calculate the total crack volume in the specimen as $1440 \pm 36 \mathrm{~mm}^{3}$. These values reveal that the microbial produced $\mathrm{CaCO}_{3}$ could only fill the $30 \%$ of the total crack volume created. Hence for such large crack widths strength regain through MICP is unlikely.

We believe that for concrete durability, protection of the steel reinforcement against corrosion is of significance. In order to protect the steel reinforcement from the aggressive substances, water tightness should be regained to a certain extent following the self-healing of the cracks. Capillary sorption test is one of the ways to quantify the water tightness of the mortar and concrete specimens. In capillary sorption tests conducted, the reference specimen represents the autogenous regain that occurs in regular cracked mortar. The uncracked mortar on the other hand represents the $100 \%$ water tightness regain. Therefore, these two values can be considered for evaluation of the water tightness regain through microbial self-healing. Based on the results, microbial self-healing provided $66 \%(0.5 \%$ ACDC) to $74 \%(1 \%$ ACDC) water tightness regain for a tested average crack width of $432 \pm 21 \mu \mathrm{m}$. Since no capillary sorption experiments were conducted for mature uncracked concrete, water tightness regain could not be calculated for mature specimens. Nevertheless, it is still known that mature microbial specimens absorbed $49-54 \%$ less water than the mature control specimens after the healing period. Mentioned major difference between autogenous healing and microbial healing is indicative for a better water tightness regain.

\section{The Healing Material and its Mechanical Properties}

In addition to the crack closure ratio, the amount of the healing material and the thickness of the sealing might influence the capillary water absorption. It is reported that autogenous healing mostly occurs at the crack mouth due to the limits in $\mathrm{CO}_{2}$ dissolution and related low concentrations inside the crack (Palin et al., 2015). One of the major advantages of microbial healing over autogenous healing is the production of $\mathrm{CO}_{2}$ inside the crack. In this process, the activity of the bacteria in the deeper parts of the crack plays a major role. Since $\mathrm{O}_{2}$ has dissolution and penetration limits similar to $\mathrm{CO}_{2}$, bacterial activity that requires aerobic conditions would be inhibited inside the crack. Contrarily, nitrate $\left(\mathrm{NO}_{3}^{-}\right)$reducing bacteria only rely on presence of $\mathrm{NO}_{3}^{-}$and organic carbon (Erşan et al., 2015a) which could be provided in mortar. Therefore, it was highly possible to observe $\mathrm{CaCO}_{3}$ formation inside the crack. Indeed, chemical and physical characterization of the filling material inside the cracks ( $5 \mathrm{~mm}<$ depth $<13 \mathrm{~mm}$ ) revealed that the control and microbial samples have different compounds. The major compound found inside the crack was $\mathrm{CaCO}_{3}$ in microbial samples regardless of their curing age. The found minerals were mostly together with bacterial footprints and bacterial remains which indicated that MICP took place. Visual analysis was further confirmed through EDX and FTIR analysis. Results indicated that inside the cracks of premature control specimens, ettringite and C-S-H were as dominant as $\mathrm{CaCO}_{3}$. Contrarily in the powder collected from microbial specimen, forms of $\mathrm{CaCO}_{3}$ were the major compounds. In mature control specimens (reference mortar and abiotic control), C-S-H was dominant inside the crack compared to $\mathrm{CaCO}_{3}$ (mostly as a result of partial carbonation).

The mechanical properties of the healing materials inside the crack were also tested to elucidate if the microbial induced $\mathrm{CaCO}_{3}$ has weaknesses compared to autogenously formed $\mathrm{CaCO}_{3}$. It is well known that microbial induced $\mathrm{CaCO}_{3}$ has pores/holes due to the growth of the minerals around the bacteria. One of the concerns is a possible decrease in mechanical properties of the microbial calcite due to the porous structure. Weaknesses in mechanical properties may cause detachment or deterioration of the $\mathrm{CaCO}_{3}$ minerals which jeopardize the maintenance of functionality regain after selfhealing. According to our findings, there is no significant difference between autogenously formed $\mathrm{CaCO}_{3}$ and microbial induced $\mathrm{CaCO}_{3}$. However, the variation in Martens hardness was higher for microbial induced $\mathrm{CaCO}_{3}$ compared to the autogenously formed $\mathrm{CaCO}_{3}$. The difference in variation could be attributed to the influence of bacteria related pores. Nevertheless, they did not significantly change the mechanical properties.

To our knowledge, the information about hardness of calcite deposits in cracks is very scarce. Reported hardness values for microbial calcite deposits (between 2.5 and $3 \mathrm{GPa}$ ) are comparable with our findings (Xu and Yao, 2014). Regardless of being autogenously formed or microbial induced, the E-modulus values of calcite minerals were between 40 and $50 \mathrm{GPa}$ which were consistent with the reported values for microbial $\mathrm{CaCO}_{3}$ deposits (40-50 GPa) (Xu and Yao, 2014).

\section{The Advantages of Self-protected Non-axenic ACDC Culture}

The recorded microbial induced self-healing performances by means of a self-protected non-axenic culture appeared to be similar to the previously reported microbial self-healing results where axenic cultures and protective carriers were used. It is reported that the production of the axenic spores becomes expensive for an industrial scale application (Silva et al., 2015a). ACDC is advantageous over reported axenic cultures in many aspects. First of all, the cultivation was done in minimal media which contains concrete admixtures as main nutrients and does not contain trace elements, vitamins, and yeast extract. Therefore, the cost for nutrients could be decreased when compared to the previously reported nutrient solutions for the growth of axenic cultures (Wang et al., 2014c; Silva et al., 2015a). Secondly, the ACDC is a self-protected culture by its layered structure that avoids the need for a protective carrier. Therefore, direct incorporation of the dried ACDC in mortar or concrete is possible. The third advantage is the easy separation 
of the ACDC from the cultivation media which avoids the centrifugation process. Since ACDC is a type of granular culture with a compact structure, the sludge volume index (SVI) values of the mixture are between 35 and $45 \mathrm{~mL} / \mathrm{g}$. Hence, simple settling period of 2-5 min enables to separate ACDC from the liquor. The separated ACDC is ready for drying without further treatment. Eventually, the mentioned advantages play a crucial role to decrease the cost of the healing agent (bacterial agent + nutrients + protective carrier). When the operational expenditure (OPEX) are considered, the production cost of ACDC is about $40 € / \mathrm{kg}$ ACDC most of which is the labor work (See Supplementary Material for calculations). If the reactor and the ACDC quality can be monitored automatically, then the labor work can be decreased by a factor 4 which makes the new OPEX cost range as $17.4 € / \mathrm{kg}$ ACDC (See Supplementary Table 2). When the capital expenditure (CAPEX) of the process is also included in the calculation, total cost of the product becomes $57.4 € / \mathrm{kg}$ ACDC (See Supplementary Material). In this study, 0.5\% ACDC in terms of $\mathrm{CDW} /$ weight cement $(0.71 \% \mathrm{ACDC} / \mathrm{w}$ cement) was found to be enough to achieve a significant microbial induced crack closure in concrete when combined with $3 \% \mathrm{Ca}\left(\mathrm{NO}_{3}\right)_{2}$ and $2 \% \mathrm{Ca}(\mathrm{HCOO})_{2}$. Therefore, for an additional cost of $\sim 136$ $€ / \mathrm{m}^{3}$ of concrete, self-healing properties of the concrete can be improved significantly (See Supplementary Table 3). Yet, these are approximate values based on the findings from a 3.2 $\mathrm{L}$ scale reactors and tests on lab scale mortar specimens. In order to have a better and brighter picture, further research on optimization and up-scaling of the process is required. The amount of nutrients and the bacterial agent required for a significantly improved self-healing performance should also be optimized to avoid over/under estimations in economic analysis.

\section{Conclusions}

- Combination of ACDC and certain concrete admixtures improved the self-healing capability of the mortar specimens.

- Microbial self-healing by means of the ACDC culture is not only effective for early age cracks but also closes the cracks occurring in mature specimens.

- Incorporation of ACDC (0.5 w/w cement) provided water tightness regain up to $74 \%$.

- Microbial induced $\mathrm{CaCO}_{3}$ minerals have similar mechanical properties to the autogenously formed $\mathrm{CaCO}_{3}$ minerals when compared through micro-indentation.

\section{REFERENCES}

Achal, V., Mukerjee, A., and Sudhakara Reddy, M. (2013). Biogenic treatment improves the durability and remediates the cracks of concrete structures. Constr. Build. Mater. 48, 1-5. doi: 10.1016/j.conbuildmat.2013.06.061

APHA, AWWA, and WEF (2012). “2540 - Solids," in Standard Methods for Examination of Water and Wastewater, 22nd Edn., eds E. W. Rice, R. B. Baird, A. D. Eaton, and L. S. Clesceri (Washington, DC: American Public Health Association).

Bang, S. S., Galinat, J. K., and Ramakrishnan, V. (2001). Calcite precipitation induced by polyurethane-immobilized Bacillus pasteurii.
- Microbial self-healing with ACDC can be distinguished from the autogenous healing by formation of $\mathrm{CaCO}_{3}$ minerals all over the inner crack surface rather than only near the crack mouth.

- Self-protected non-axenic cultures are an economically feasible alternative for development of microbial self-healing concrete.

\section{AUTHOR CONTRIBUTIONS}

YE-The study was held in the context of the author's $\mathrm{PhD}$ research on development of microbial self-healing concrete. Experimental design and experimental work, data interpretation, and manuscript preparation was done by this author. EGExperimental work, data interpretation, and typing of the results was done by this author regarding to the indentation experiments presented for microbial induced $\mathrm{CaCO}_{3}$ and autogenously formed $\mathrm{CaCO}_{3}$. GL and $\mathrm{CL}-$ Significant guidance was provided by these authors during the interpretation of indentation results and revision of the manuscript. Moreover, they have provided the equipment required for the relevant analyses. ND-As the co-supervisor and the corresponding author of the article, she improved the quality of the article and the experimental designs by her expertise on concrete and self-healing phenomena. NBAs the main supervisor of the $\mathrm{PhD}$ candidate, he provided significant guidance during the production of the bacterial culture, experimental design, and data interpretation.

\section{ACKNOWLEDGMENTS}

The research leading to these results has received funding from the European Union Seventh Framework Programme [FP7/2007-2013] under grant agreement $\mathrm{n}^{\circ} 290308$ (Marie Curie action SHeMat "Training Network for Self-Healing Materials: from Concepts to Market"). Additionally, funding was received from the COST Action TU 1404 for the indentation measurements at Ecole des Mines de Douai under supervision of Prof. Dr. Denis Damidot.

\section{SUPPLEMENTARY MATERIAL}

The Supplementary Material for this article can be found online at: http://journal.frontiersin.org/article/10.3389/fmicb. 2015.01228

Enzyme Microb. Technol. 28, 404-409. doi: 10.1016/S0141-0229(00) 00348-3

Chicot, D. (2009). Hardness length-scale factor to model nano- and micro-indentation size effects. Mater. Sci. Eng. A 499, 454-461. doi: 10.1016/j.msea.2008.09.040

Edvardsen, C. (1999). Water permeability and autogenous healing of cracks in concrete. ACI Mater. J. 96, 448-454.

Erşan, Y. Ç., Boon, N., and De Belie, N. (2015b). "Microbial self-healing concrete: denitrification as an enhanced and environment-friendly approach," in 5th International Conference on Self-Healing Materials (Durham, NC). 
Erşan, Y. Ç., De Belie, N., and Boon, N. (2015a). Microbially induced $\mathrm{CaCO}_{3}$ precipitation through denitrification: an optimization study in minimal nutrient environment. Biochem. Eng. J. 101, 108-118. doi: 10.1016/j.bej.2015. 05.006

Erşan, Y. Ç., and Erguder, T. H. (2013). The effects of aerobic/anoxic period sequence on aerobic granulation and COD/ $\mathrm{N}$ treatment efficiency. Bioresour. Technol. 148, 149-156. doi: 10.1016/j.biortech.2013.08.096

Erşan, Y. Ç., and Erguder, T. H. (2014). The effect of seed sludge type on aerobic granulation via anoxic-aerobic operation. Environ. Technol. 35, 2928-2939. doi: 10.1080/09593330.2014.925513

Erşan, Y. Ç., Silva, F. B., Boon, N., Verstraete, W., and De Belie, N. (2015c). Screening of bacteria and concrete compatible protection materials. Constr. Build. Mater. 88, 196-203. doi: 10.1016/j.conbuildmat.2015. 04.027

Erşan, Y. Ç., Verbruggen, H., De Graeve, I., Verstraete, W., De Belie, N., and Boon, $\mathrm{N}$. (accepted). Nitrate reducing $\mathrm{CaCO} 3$ precipitating bacteria survive in mortar and inhibit steel corrosion. Cem. Concr. Res.

Gao, D., Liu, L., Liang, H., and Wu, W.-M. (2011). Aerobic granular sludge: characterization, mechanism of granulation and application to wastewater treatment. Crit. Rev. Biotechnol. 31, 137-152. doi: $10.3109 / 07388551.2010 .497961$

Harwood, C., and Cutting, S. (1990). Molecular Biological Methods for Bacillus. Chichester: John Wiley \& Sons.

Hay, J. C., Bolshakov, A., and Pharr, G. M. (2008). A critical examination of the fundamental relations used in the analysis of nanoindentation data. J. Mater. 14, 2296-2305. doi: 10.1557/JMR.1999.0306

Hughes, T. L., Methven, C. M., Jones, T. G., Pelham, S. H., Fletcher, P., and Hall, C. (1995). Determining cement composition by fourier transform infrared spectroscopy. Adv. Cem. Based Mater. 2, 91-104. doi: 10.1016/10657355(94)00031-X

Li, V. C., and Herbert, E. (2012). Robust self-healing concrete for sustainable infrastructure. J. Adv. Concr. Technol. 10, 207-218. doi: 10.3151/jact.10.207

Lv, Y., Wan, C., Liu, X., Zhang, Y., Lee, D.-J., and Tay, J.-H. (2013). Drying and re-cultivation of aerobic granules. Bioresour. Technol. 129, 700-703. doi: 10.1016/j.biortech.2012.12.178

Mollah, M. Y. A., Yu, W., Schennach, R., and Cocke, D. L. (2000). A Fourier transform infrared spectroscopic investigation of the early hydration of Portland cement and the influence of sodium lignosulfonate. Cem. Concr. Res. 30, 267-273. doi: 10.1016/S0008-8846(99)00243-4

Oliver, W. C., and Pharr, G. M. (1992). An improved technique for determining hardness and elastic modulus using load and displacement sensing indentation experiments. J. Mater. Res. 7, 1564-1583. doi: 10.1557/JMR.1992.1564

Oliver, W. C., and Pharr, G. M. (2004). Measurement of hardness and elastic modulus by instrumented indentation: advances in understanding and refinements to methodology. J. Mater. Res. 19, 3-20. doi: 10.1557/jmr.2004.19.1.3

Palin, D., Wiktor, V., and Jonkers, H. M. (2015). Autogenous healing of marine exposed concrete: characterization and quantification through visual crack closure. Cem. Concr. Res. 73, 17-24. doi: 10.1016/j.cemconres.2015.02.021

Ramachandran, S. K., Ramakrishnan, V., and Bang, S. S. (2001). Remediation of concrete using micro-organisms. ACI Mater. J. 98, 3-9.

Reinhardt, H.-W., and Jooss, M. (2003). Permeability and self-healing of cracked concrete as a function of temperature and crack width. Cem. Concr. Res. 33, 981-985. doi: 10.1016/S0008-8846(02)01099-2

Ren, T. T., Liu, L., Sheng, G. P., Liu, X. W., Yu, H. Q., Zhang, M. C., et al. (2008). Calcium spatial distribution in aerobic granules and its effects on granule structure, strength and bioactivity. Water Res. 42, 3343-3352. doi: 10.1016/j.watres.2008.04.015

Sierra-Beltran, M. G., Jonkers, H. M., and Ortiz, M. (2015). "Field application of self-healing concrete with natural fibres as linings for irrigation canals in Ecuador," in Fifth International Conference on Self-Healing Materials (Durham, NC), 32 .

Silva, F. B., Boon, N., De Belie, N., and Verstraete, W. (2015a). Industrial application of biological self-healing concrete: challenges and economical feasibility. J. Commer. Biotechnol. 21, 31-38. doi: 10.5912/jcb662
Silva, F., De Belie, N., Boon, N., and Verstraete, W. (2015b). Production of non-axenic ureolytic spores for self-healing concrete applications. Constr. Build. Mater. 93, 1034-1041. doi: 10.1016/j.conbuildmat.2015. 05.049

Trezza, M. A., Valle, A., and Aires, O. B. (2007). Hydration study of ordinary portland cement in the presence of zinc ions. Mater. Res. 10, 331-334. doi: 10.1590/S1516-14392007000400002

Van Tittelboom, K., and De Belie, N. (2013). Self-healing in cementitious materials-a review. Materials 6, 2182-2217. doi: 10.3390/ma60 62182

Van Tittelboom, K., De Belie, N., Van Loo, D., and Jacobs, P. (2011). Self-healing efficiency of cementitious materials containing tubular capsules filled with healing agent. Cem. Concr. Compos. 33, 497-505. doi: 10.1016/j.cemconcomp.2011.01.004

Wan, J., Bessière, Y., and Spérandio, M. (2009). Alternating anoxic feast/aerobic famine condition for improving granular sludge formation in sequencing batch airlift reactor at reduced aeration rate. Water Res. 43, 5097-5108. doi: 10.1016/j.watres.2009.08.045

Wang, J. (2013). Self-Healing Concrete by Means of Immobilized Carbonate Precipitating Bacteria. Ph.D. thesis, Ghent University. ISBN: 978-90-8578583-5.

Wang, J., De Belie, N., and Verstraete, W. (2012a). Diatomaceous earth as a protective vehicle for bacteria applied for self-healing concrete. J. Ind. Microbiol. Biotechnol. 39, 567-577. doi: 10.1007/s10295-011-1037-1

Wang, J., Dewanckele, J., Cnudde, V., Van Vlierberghe, S., Verstraete, W., and De Belie, N. (2014a). X-ray computed tomography proof of bacterialbased self-healing in concrete. Cem. Concr. Compos. 53, 289-304. doi: 10.1016/j.cemconcomp.2014.07.014

Wang, J., Snoeck, D., Van Vlierberghe, S., Verstraete, W., and De Belie, N. (2014b). Application of hydrogel encapsulated carbonate precipitating bacteria for approaching a realistic self-healing in concrete. Constr. Build. Mater. 68, 110-119. doi: 10.1016/j.conbuildmat.2014.06.018

Wang, J., Soens, H., Verstraete, W., and De Belie, N. (2014c). Self-healing concrete by use of microencapsulated bacterial spores. Cem. Concr. Res. 56, 139-152. doi: 10.1016/j.cemconres.2013.11.009

Wang, J., Van Tittelboom, K., De Belie, N., and Verstraete, W. (2012b). Use of silica gel or polyurethane immobilized bacteria for self-healing concrete. Constr. Build. Mater. 26, 532-540. doi: 10.1016/j.conbuildmat.2011.06.054

Wiktor, V., and Jonkers, H. M. (2011). Quantification of crack-healing in novel bacteria-based self-healing concrete. Cem. Concr. Compos. 33, 763-770. doi: 10.1016/j.cemconcomp.2011.03.012

$\mathrm{Xu}$, J., and Yao, W. (2014). Multiscale mechanical quantification of self-healing concrete incorporating non-ureolytic bacteria-based healing agent. Cem. Concr. Res. 64, 1-10. doi: 10.1016/j.cemconres.2014.06.003

Yang, Y., Lepech, M. D., Yang, E.-H., and Li, V. C. (2009). Autogenous healing of engineered cementitious composites under wet-dry cycles. Cem. Concr. Res. 39, 382-390. doi: 10.1016/j.cemconres.2009.01.013

Yu, H. Q. M., Tay, J. H., and Fang, H. H. P. (2001). The roles of calcium in sludge granulation during uasb reactor start-up. Water Res. 35, 1052-1060. doi: 10.1016/S0043-1354(00)00345-6

Yu, P., Kirkpatrick, R. J., Poe, B., McMillan, P. F., and Cong, X. (2004). Structure of calcium silicate hydrate (C-S-H): near-, mid-, and far-infrared spectroscopy. J. Am. Ceram. Soc. 82, 742-748. doi: 10.1111/j.1151-2916.1999.tb01826.x

Conflict of Interest Statement: The authors declare that the research was conducted in the absence of any commercial or financial relationships that could be construed as a potential conflict of interest.

Copyright (c) 2015 Erșan, Gruyaert, Louis, Lors, De Belie and Boon. This is an open-access article distributed under the terms of the Creative Commons Attribution License (CC BY). The use, distribution or reproduction in other forums is permitted, provided the original author(s) or licensor are credited and that the original publication in this journal is cited, in accordance with accepted academic practice. No use, distribution or reproduction is permitted which does not comply with these terms. 